\title{
XPS of cold pressed multilayered and freestanding delaminated 2D thin films of Mo2TiC2Tz and Mo2Ti2C3Tz (MXenes)
}

J oseph Halim, Kevin M. Cook, Per Eklund, J ohanna Rosén and Michel Barsoum

The self-archived postprint version of this journal article is available at Linköping University Institutional Repository (DiVA):

http:// urn.kb.se/ resolve?urn=urn:nbn:se:liu:diva- 160962

N.B.: When citing this work, cite the original publication.

Halim, J., Cook, K. M., Eklund, P., Rosén, J ., Barsoum, M., (2019), XPS of cold pressed multilayered and freestanding delaminated 2D thin films of Mo2TiC2Tz and Mo2Ti2C3Tz (MXenes), Applied Surface Science, 494, 1138-1147. https:// doi.org/ 10.1016/j.apsusc.2019.07.049

Original publication available at:

https:// doi.org/ 10.1016/j.apsusc.2019.07.049

Copyright: Elsevier

http:// www.elsevier.com/

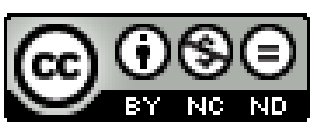




\title{
XPS of Cold Pressed Multilayered and Freestanding Delaminated 2D Thin Films of $\mathrm{Mo}_{2} \mathrm{TiC}_{2} \mathrm{~T}_{\mathrm{z}}$ and $\mathrm{Mo}_{2} \mathrm{Ti}_{2} \mathrm{C}_{3} \mathrm{~T}_{\mathrm{Z}}$ (MXenes)
}

Joseph Halim $^{1 \dagger^{*}}$, Kevin M. Cook ${ }^{2 \dagger^{*}}$, Per Eklund ${ }^{1}$, Johanna Rosen ${ }^{1}$, and Michel W. Barsoum ${ }^{1,3^{*}}$

${ }^{1}$ Thin Film Physics Division, Department of Physics, Chemistry and Biology (IFM), Linköping University, SE-583 31 Linköping, Sweden.

${ }^{2}$ Materials Engineering Laboratory, Linde Technology Center, Praxair, Inc. a member of the Linde Group, Tonawanda, NY 14150, USA.

${ }^{3}$ Department of Materials Science \& Engineering, Drexel University, Philadelphia, PA 19104, USA.

${ }^{\dagger}$ Authors have contributed equally to this work

Corresponding authors.

E-mail addresses: barsoumw@ drexel.edu (M.W. Barsoum)

joseph.halim@liu.se (J. Halim)

kevin_cook@praxair.com (K.M. Cook)

\begin{abstract}
MXenes, transition metal carbides that are synthesized from the top down by etching of their 3D parent layered solids, the MAX phases, are the latest family of the two-dimensional solids discovered. When the A layers - mostly $\mathrm{Al}$ - are etched they are replaced by surface terminations, $\mathrm{T}_{\mathrm{z}}$ mainly comprised of $\mathrm{O}-, \mathrm{OH}-$ and F-terminations. One of the few techniques capable of quantifying these surface terminations is X-ray photoelectron spectroscopy, XPS. Herein, we undertook an XPS study of the out-of-plane ordered MXenes, $\mathrm{Mo}_{2} \mathrm{TiC}_{2} \mathrm{~T}_{\mathrm{z}}$ and $\mathrm{Mo}_{2} \mathrm{Ti}_{2} \mathrm{C}_{3} \mathrm{~T}_{\mathrm{z}}$, in both multilayered, ML, cold pressed and delaminated thin film forms. The harsh conditions needed to etch these MAX phases into MLs, results in their partial oxidation. The hydroxide used to delaminate the MLs results in further oxidation and a reduction in the F-content. In all cases, etching resulted in a decrease in the Ti to Mo ratio implying that the former atoms are selectively etched. In all but the $\mathrm{ML} \mathrm{Mo} \mathrm{TiC}_{2} \mathrm{~T}_{\mathrm{z}}$ case, the Mo to $\mathrm{C}$ ratio was also reduced. It follows that the loss of $\mathrm{Ti}$ also results in the loss of $\mathrm{C}$ atoms. With the exception of the $\mathrm{ML} \mathrm{Mo}_{2} \mathrm{Ti}_{2} \mathrm{C}_{3} \mathrm{~T}_{\mathrm{Z}}$ case, the number of termination moles per formula unit, $\mathrm{z}$, was $>2$, which is energetically unfavorable and thus unlikely. However, if one assumes that not all of the $\mathrm{O}$ signal is coming from terminations but rather from $\mathrm{O}$ atoms that replace $\mathrm{C}$ atoms in the $\mathrm{MX}$ blocks, then $\mathrm{z} \approx 2$. This work is an important step in quantifying and understanding the effects of etching on terminations and structure in these Mo and Ti-based MXenes.
\end{abstract}




\section{Keywords:}

Mo-based MXenes, X-ray photoelectron spectroscopy, surface chemistry, 2D materials

\section{Highlights}

- Surface chemistry of out-of-plane chemically ordered $\mathrm{Mo}_{2} \mathrm{TiC}_{2} \mathrm{~T}_{\mathrm{Z}}$ and $\mathrm{Mo}_{2} \mathrm{Ti}_{2} \mathrm{C}_{3} \mathrm{~T}_{\mathrm{z}}$ cold pressed multilayered disks and delaminated thin films MXenes were characterized and studied by XPS for the first time.

- Surface terminations of -O, -OH, -F, were quantified

- Change in the surface termination composition towards less $-\mathrm{F}$ and more -O and -OH after delamination

- In all cases, etching resulted in a decrease in the Ti to Mo ratio implying that the former is selectively etched.

- A concomitant reduction in $\mathrm{C}$ to Ti ratio suggests that some $\mathrm{C}$ atoms are lost when the $\mathrm{Ti}$ atoms are etched out

- Not all of the $\mathrm{O}$ signal comes from terminations per se. Some of it most probably comes from $\mathrm{O}$ atoms occupying vacant $\mathrm{C}$ sites.

\section{Introduction}

Two-dimensional (2D) materials have attracted tremendous interest in the scientific community owing to their extraordinary electronic, chemical, optical, mechanical and structural properties that result from their reduced dimensionality compared to their bulk 3D counterparts [1]. Today graphene is probably and most extensively researched 2D material [2]. However, other 2D materials have been of growing interest such as hexagonal boron nitride (hBN) [3], transitionmetal dichalcogenides (TDMs) such as $\mathrm{MoS}_{2}$ [4], transition metal oxides and hydroxides, including clays [5], and mono-elemental 2D materials such as silicene [6], phosphorene [7], and germanene [8].

Transition metal carbides and nitrides labelled "MXene" have been recently added to the list of 2D materials [9-11]. MXenes have a general formula of $M_{n+1} X_{n} T_{z}(n=1$ to 3), where $M$ represents an early transition metal, $\mathrm{X}$ is $\mathrm{C}$ and/or $\mathrm{N}$, and $\mathrm{T}_{\mathrm{Z}}$ stands for the surface functional groups $\left(\mathrm{OH}, \mathrm{O}\right.$ and/or F) [12, 13]. Currently, > 25 family members have been reported such as $\mathrm{Ti}_{3} \mathrm{C}_{2} \mathrm{~T}_{2}$, $\mathrm{Ti}_{2} \mathrm{CT}_{\mathrm{z}}, \mathrm{Ti}_{4} \mathrm{~N}_{3} \mathrm{~T}_{\mathrm{z}}$ and $\mathrm{Nb}_{2} \mathrm{CT}_{\mathrm{z}}[11,12,14-19]$. MXenes are synthetized via selective chemical etching of the A element (e.g., $\mathrm{Al}, \mathrm{Ga}$ or $\mathrm{Si}$ ) from the MAX phases [9, 20, 21]. The latter is a family of layered hexagonal transition metal carbides, of chemical formula $M_{n+1} A X_{n}$, where $A$ is an A-group element (mostly from groups 13 and 14) [22]. The chemical etching is performed using hydrofluoric acid, HF, [9] mixtures of lithium fluoride, $\mathrm{LiF}$, and hydrochloric acid, $\mathrm{HCl}$ [23], $\mathrm{HF}$ and $\mathrm{HCl}$ [24], or ammonium biflouride, $\mathrm{NH}_{4} \mathrm{HF}_{2}$ [25]. The $\mathrm{F}$ ions react with the A element, by far the most common being $\mathrm{Al}$, and replace it with surface termination groups " $\mathrm{T}_{\mathrm{z}}$ ". 
MXenes have shown promise in a plethora of applications including energy storage, including batteries [26-28], supercapacitors [23, 29], and fuel cells [30], transparent conducting electrodes [25], photocatalysts [31], water treatment [32,33] and sensors [34] among many others.

Recently, it has been shown that ordered "double M" MAX structures, containing two metals ( $\mathrm{M}^{\prime}$ and $\mathrm{M}^{\prime}$ ') can be synthetized [35,36] and converted to their MXenes [14]. In such structures, one $\mathrm{M}$ element, such as Mo, occupies the outer layers of the $\mathrm{M}_{\mathrm{n}+1} \mathrm{X}_{\mathrm{n}}$ blocks, while the other $\mathrm{M}$ element, such as Ti, occupies the inner M layers. In the Mo-Ti system two such ordered MXenes $\mathrm{Mo}_{2} \mathrm{TiC}_{2} \mathrm{~T}_{\mathrm{z}}$ and $\mathrm{Mo}_{2} \mathrm{Ti}_{2} \mathrm{C}_{3} \mathrm{~T}_{\mathrm{z}}$ have been synthesized. (Fig. 1).

Experimental results for both compounds show a decrease in resistivity with increased temperature. Fitting the results demonstrated that two conduction mechanisms are operating in series. At lower temperatures, variable range hopping between individual MXene flakes is operative; at higher temperatures some of the carriers are thermally activated [37]. The identity of the functional groups present should impact the properties. As predicted theoretically and demonstrated experimentally, the functional groups have an influence on various properties including capacitance [26, 38] and density of states (DOS) [39]. Recent spin-polarized DFT calculations have predicted that changing the surface termination groups for $\mathrm{Mo}_{2} \mathrm{TiC}_{2} \mathrm{~T}_{\mathrm{z}}$ and $\mathrm{Mo}_{2} \mathrm{Ti}_{2} \mathrm{C}_{3} \mathrm{~T}_{\mathrm{z}}$ should affect their electronic properties [40]. For instance, $\mathrm{Mo}_{2} \mathrm{TiC}_{2} \mathrm{~T}_{\mathrm{z}}$ and $\mathrm{Mo}_{2} \mathrm{Ti}_{2} \mathrm{C}_{3} \mathrm{~T}_{\mathrm{z}}$ terminated with $-\mathrm{OH},-\mathrm{F}$, or mixtures of $-\mathrm{OH}$ and $-\mathrm{F}$ were predicted to be semiconductors with a small band gap of $\sim 0.05 \mathrm{eV}$. However, $\mathrm{Mo}_{2} \mathrm{TiC}_{2}$ and $\mathrm{Mo}_{2} \mathrm{Ti}_{2} \mathrm{C}_{3}$ terminated with $-\mathrm{O}$ were predicted to be metallic.

In general, it is non-trivial to quantify surface terminations. One of the few techniques capable of doing so relatively easily is X-ray photoelectron spectroscopy, XPS. In previous studies, XPS was used to identify the compositions and stoichiometries of various MXenes, including their terminations [13, 17, 24, 39]. These analyses have shed light on the functional groups, their relative amounts with respect to time and other variables [13] and how they affect the structure and electrochemical properties of MXenes [41]. Given the importance of terminations on properties it is imperative to quantify them accurately. Herein, we present the results of an XPS study of $\mathrm{Mo}_{2} \mathrm{TiC}_{2} \mathrm{~T}_{\mathrm{z}}$ and $\mathrm{Mo}_{2} \mathrm{Ti}_{2} \mathrm{C}_{3} \mathrm{~T}_{\mathrm{z}}$ as a function of flake morphology.

Before discussing Mo-based MXenes, it is important to summarize our latest understanding of terminations present on the surfaces of the most studied MXene to date, viz. $\mathrm{Ti}_{3} \mathrm{C}_{2} \mathrm{~T}_{\mathrm{z}}$. It has been recently shown using in situ XPS that when $\mathrm{Ti}_{3} \mathrm{AlC}_{2}$ MAX phase is etched in $\mathrm{HF}$, the more favored sites - labeled A in Fig. 1 - are preferentially occupied by F and the energetically less favored sites - labelled B in Fig. 1 - are occupied by $\mathrm{O}$ atoms [42]. Note that the A-sites are sitting in an FCC arrangement relative to the underlying $\mathrm{C}$ layer, whereas the B-sites are in an $\mathrm{HCP}$ arrangement. The $\mathrm{O}$ binding energy (BE) of the A-site was concluded to be $531.3 \mathrm{eV}$; the $\mathrm{BE}$ of the $\mathrm{B}$-site was $529.9 \mathrm{eV}$. As discussed below, this distinction is important in this work. We also note that so long as the $\mathrm{F}$ are present, they populate the A-sites. It was only after heating to $750{ }^{\circ} \mathrm{C}$ for $\approx 2.5 \mathrm{~h}$ in high vacuum that the $\mathrm{F}$ was removed from the surface.

Since the samples studied here were comprised of both molybdenum oxides (arising from surface oxidation) and carbides (MXenes), it is also useful to summarize previous XPS studies of these materials. Molybdenum oxides are commonly studied as catalyst materials, as their 
electronic properties are known to change with Mo oxidation state, though Mo (VI) is more stable than Mo (IV) and (V) [43-45]. Analysis of molybdenum oxides by XPS has shown the deconvolution of Mo spectra to be complex, namely in that Mo (IV), Mo (V), and Mo (VI) all may all occur, with Mo (IV) present as two spin-orbit doublets [46, 47]. In general, the Mo 3d and O 1s spectra of these oxides present well-defined ranges for binding energies associated with known oxidation states. The Mo $3 \mathrm{~d}$ and $\mathrm{O}$ 1s binding energies of molybdenum carbide, $\mathrm{Mo}_{2} \mathrm{C}$, have been well-characterized by Greczynski et al. in a recent study [48]. Molybdenum carbides are also

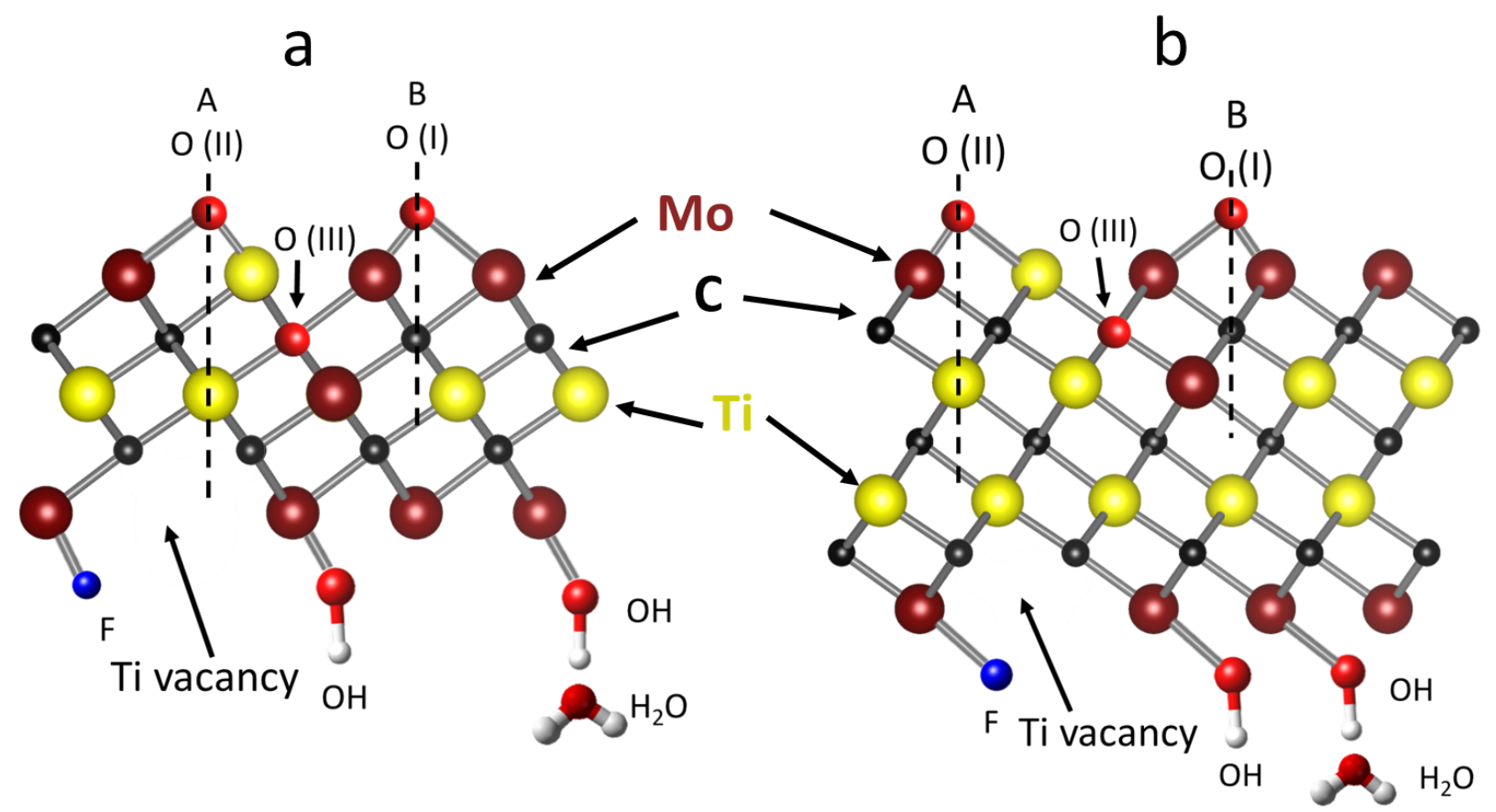

studied as catalytic materials [49], including as partially oxidized oxycarbides [50-52]. The deconvolution of the Mo 3d region for the oxycarbides have been reported to contain peaks for Mo (IV), Mo (V), and Mo (VI) [50-52]. These oxycarbides are of particular interest to this study, as the MXenes have a tendency to oxidize.

Figure 1: Crystal structure of single layers of, (a) $\mathrm{Mo}_{2} \mathrm{TiC}_{2} \mathrm{~T}_{\mathrm{z}}(21)$ and, (b) $\mathrm{Mo}_{2} \mathrm{Ti}_{2} \mathrm{C}_{3} \mathrm{~T}_{\mathrm{z}}$ (22). Three common terminations are shown: $-\mathrm{O},-\mathrm{OH}$ and $-\mathrm{F}$, in addition to adsorbed $\mathrm{H}_{2} \mathrm{O}$. $\mathrm{O}$ (II) and $\mathrm{O}$ (I) are the $\mathrm{O}$ terminations occupying $\mathrm{A}$ or $\mathrm{FCC}$ site and $\mathrm{B}$ or $\mathrm{HCP}$ site, respectively. $\mathrm{O}$ (III) is an $\mathrm{O}$ occupying $\mathrm{C}$ vacancy.

\section{Experimental Details}

2.1 Synthesis of cold pressed multilayered, $M L, M 0_{2} T_{i C} T_{z}$ and $M_{2} T_{2} C_{3} T_{z} \operatorname{discs}$ 
Multilayered, ML, flakes were prepared by immersing $2 \mathrm{~g}$ of $\mathrm{Mo}_{2} \mathrm{TiAlC}_{2}$ or $\mathrm{Mo}_{2} \mathrm{Ti}_{2} \mathrm{AlC}_{3}$ powders [35, 36], respectively, in $20 \mathrm{ml}$ of $50 \% \mathrm{HF}$ acid (Fisher Scientific, Fair Lawn, NJ) (HF) solution and holding at $55^{\circ} \mathrm{C}$ for $48 \mathrm{~h}$ for $\mathrm{Mo}_{2} \mathrm{TiAlC}_{2}$ and $90 \mathrm{~h}$ for $\mathrm{Mo}_{2} \mathrm{Ti}_{2} \mathrm{AlC}_{3}$, while stirring the solution using a Teflon coated magnetic bar. The mixtures were washed several times with deionized (DI) water, centrifuged at $5000 \mathrm{rpm}$ for $1 \mathrm{~min}$ per cycle and finally decanted. The washing procedure was stopped once the supernatant reached a $\mathrm{pH}$ of $\sim 6$. The residue was then mixed with $\sim 20 \mathrm{ml}$ of DI and vacuum filtered on a nanoporous polypropylene membrane (3501 Coated PP, Celgard, USA). The yield for ML-21 and ML-22 was 90 and 70 wt.\%, respectively. Upon drying under vacuum for $18 \mathrm{~h}$, the powder obtained was uniaxially cold pressed in a steel die to a load corresponding to a stress of $\approx 1 \mathrm{GPa}$ to make discs $0.5 \mathrm{~mm}$ thick and $20 \mathrm{~mm}$ in diameter. The $\mathrm{ML} \mathrm{Mo} \mathrm{TiC}_{2} \mathrm{~T}_{\mathrm{z}^{-}}$and $\mathrm{Mo}_{2} \mathrm{Ti}_{2} \mathrm{C}_{3} \mathrm{~T}_{\mathrm{z}^{-}}$based films will henceforth be referred to as ML21 and ML-22, respectively.

\subsection{Synthesis of delaminated, $d, M_{2} T_{i C} T_{z}$ and $M_{2} T_{2} C_{3} T_{z}$ thin films}

Thin films made by filtering colloidal suspensions will henceforth be referred to as d-21 and d-22. The latter were prepared by mixing $2 \mathrm{~g}$ of the ML filtered powders with $20 \mathrm{ml}$ of 54-56 wt. \% tetrabutylammonium hydroxide (TBAOH) (Sigma Aldrich, St. Louis, MO, USA) and stirring for $1 \mathrm{~h}$ at RT. More details can be found in Ref. [53]. The resulting mixture was centrifuged at 5000 rpm for $5 \mathrm{~min}$ and the supernatant was decanted and saved. The supernatant was then washed 3 times with $40 \mathrm{ml} \mathrm{DI}$, centrifuged at $5000 \mathrm{rpm}$ for 1 min per cycle and finally decanted to remove any leftover TBAOH. The sediment was mixed with $100 \mathrm{ml}$ of DI water, deaerated using Ar gas, and followed by sonication in an ice cooled ultrasonic bath for $1 \mathrm{~h}$. The mixture was then centrifuged for $1 \mathrm{~h}$ at $5000 \mathrm{rpm}$, and the supernatant was vacuum filtered onto a nanoporous polypropylene membrane (Celgrard 3501, $0.064 \mu \mathrm{m}$ pore size, Celgrad LLC) in air. The d-21 and d-22 films were readily separated from the polymer membranes to obtain free-standing films, $\approx 5$ $\mu \mathrm{m}$ thick. Finally, the films were annealed in a vacuum oven $(100 \mathrm{KPa})$ at $200^{\circ} \mathrm{C}$ for $18 \mathrm{~h}$.

\subsection{X-ray photoelectron spectroscopy analysis}

This work builds on our previous XPS work, wherein we outlined the important variables one must be cognizant of during the measurements [13]. The measurements were performed using a surface analysis system (Physical Electronics, VersaProbe 5000, Chanhassen, MN) employing a $100 \mu \mathrm{m}$ monochromatic Al-K $\alpha$ X-ray beam to irradiate the sample surface. Photoelectrons were collected by a $180^{\circ}$ takeoff angle between the sample surface and the path to the analyzer. Charge neutralization was performed using a dual beam charge neutralizer irradiating low-energy electrons and ion beam to avoid shift in the recorded binding energy (BE). Survey spectra were taken at a pass energy of $117.5 \mathrm{eV}$, with a step size of $0.1 \mathrm{eV}$.

High-resolution spectra for Mo 3d, Ti 2p, C 1s, O 1s, F 1s, and Al 2p were taken at a pass energy of $11.75 \mathrm{eV}$ with a step size of $0.05 \mathrm{eV}$. The binding energy scale of all XPS spectra was referenced to the Fermi-edge $\left(E_{f}\right)$, which was set to a BE of zero eV. To obtain the spectra, the samples were mounted on double-sided tape and were electrically connected to the sample holder using a copper wire. All measurements were performed without Ar ion sputtering. The quantification, using the obtained core-level intensities, and peak fitting of the core-level spectra was performed using a software package (CasaXPS Version 2.3.16 RP 1.6). Prior to both the quantification and peak 
fitting the background contributions were subtracted using a Shirley function. The area ratios of the Mo $3 \mathrm{~d}_{5 / 2}$ and $3 \mathrm{~d}_{3 / 2}$ peaks were constrained to $3: 2$; those of the Ti $2 \mathrm{p}_{3 / 2}$ and $2 \mathrm{p}_{1 / 2}$ peaks were constrained to $2: 1$.

\section{Results}

\subsection{Chemical characterization}

Typical high-resolution XPS spectra in the Mo 3d, Ti 2p, and O 1s regions - along with their peak fits - of ML-21 and $d-21$ films are plotted in Figs. 2 a-c, respectively. The respective spectra, and their fits, for the ML-22 and $d-22$ films are shown in Figs. 2 d-f. The spectra in the C $1 \mathrm{~s}$ and $\mathrm{F} 1 \mathrm{~s}$ regions for the ML-21 and $d-21$ films are shown in Fig. 3a and b, respectively. The respective spectra for the ML-22 and $d-22$ films are shown in Figs. $3 \mathrm{c}$ and d.

The peak fitting results for the various species are summarized in Tables 1-3 and Tables S1 and S2 in supplementary information. The various surface moieties fit within the XPS spectra are depicted in Fig. $1 \mathrm{a}$ and $\mathrm{b}$ for the 21 and 22 compositions, respectively. The high-resolution spectra of each element are discussed below.

\section{Molybdenum:}

Figure 2a shows the high-resolution XPS spectra of the Mo 3d region for ML-21 (lower spectrum) and $d-21$ (upper spectrum). Table 1 summarizes the peak energies, their full-width-athalf maximum, FWHM, and their molar ratios for the 4 samples examined. In all samples, the majority ( $>79 \%$ ) of the signal can be ascribed to Mo atoms that reside in the $\mathrm{Mo}_{2} \mathrm{TiC}_{2} \mathrm{~T}_{\mathrm{z}} \mathrm{MXene}$. This species belongs to MXene Mo atoms, viz. Mo atoms bonded to both C atoms - in the MX blocks - and surface terminations, $\mathrm{T}_{\mathrm{z}}$, or "C-Mo-Tz." (see Figure 1). At $229.6 \mathrm{eV}$, the BE of this peak is $1.5 \mathrm{eV}$ higher than that for the Mo in the parent MAX phase [14]. This BE shift is typical of MXenes and occurs when the Al layers are replaced by more electronegative species, such as $\mathrm{O}$ and F.[13, 17] Gratifyingly, this $\mathrm{BE}$ is identical to the $\mathrm{BE}$ in $\mathrm{Mo}_{2} \mathrm{CT}_{\mathrm{z}}$ [17].

A minority $-8 \%$ to $14 \%$ - of the Mo spectrum was ascribed to $\mathrm{Mo}^{5+}$ and $\mathrm{Mo}^{6+}$, with peaks at BEs at 231.2 and/or $232.6 \mathrm{eV}$, respectively, which are due to surface oxides [47]. Only two species were needed to fit the $d-\mathrm{Mo}_{2} \mathrm{Ti}_{2} \mathrm{C}_{2}$ spectrum. For the ML-21 sample, on the other hand, four peaks were needed. The one at $228.4 \mathrm{eV}$ was ascribed to the binary carbide, $\mathrm{Mo}_{2} \mathrm{C}$, which was present as a secondary phase $(\sim 5.7$ at. $\%)$ in the original MAX phase [36]. The slight differences in the BE of the $\mathrm{Mo}^{6+}$ can be attributed to the low intensity of their peaks and the concomitant difficulties in fitting the results. 

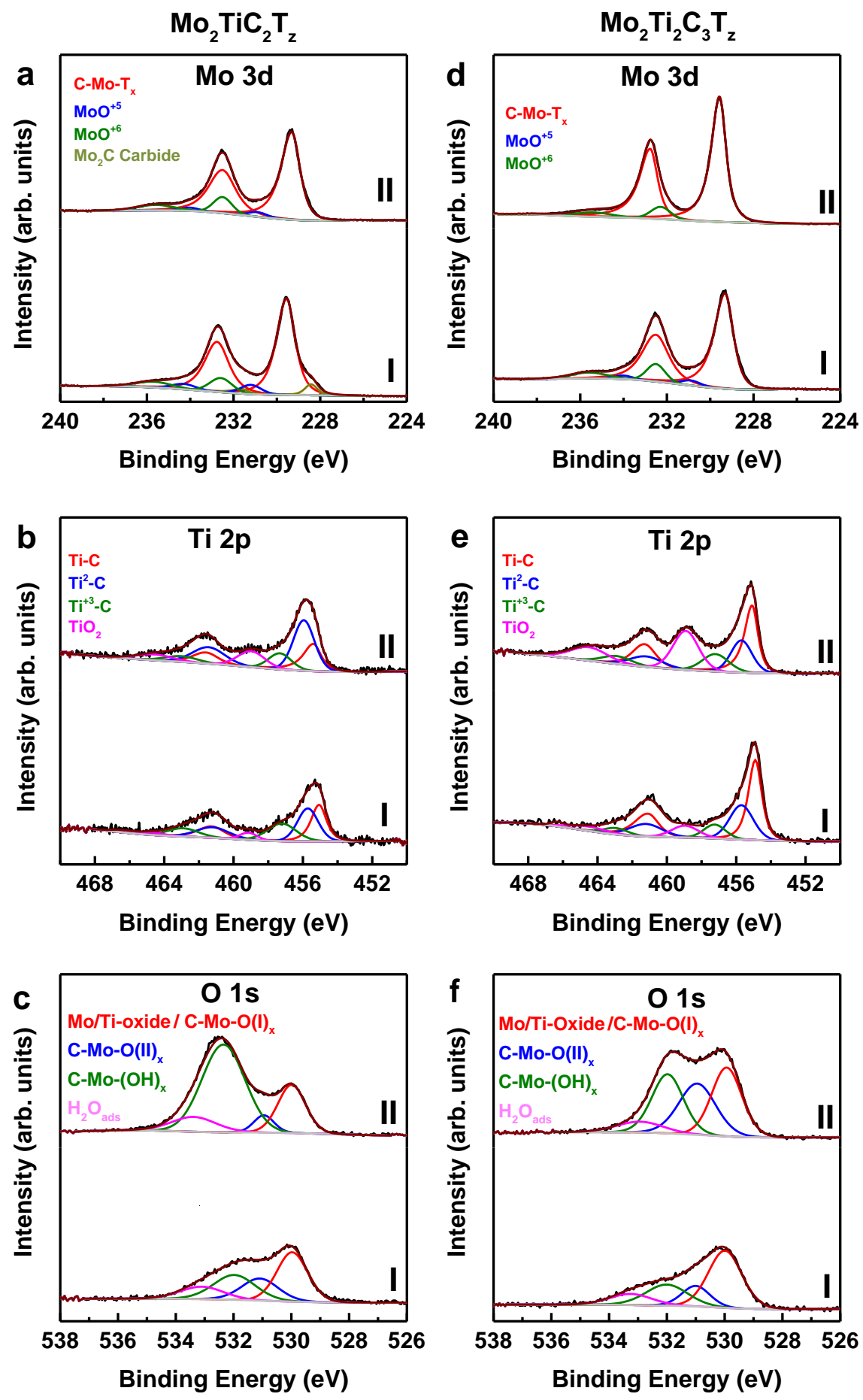

Figure 2: XPS spectra with curve fitting for: (a) Mo 3d, (b) Ti 2p, (c) O 1s regions for ML-(I) and delaminated (II) thin films for 21 composition. (d) same as (a) for 22 (e) same as (b), for 22, (f) same as (c), for 22 composition. Peaks shown represent various species assumed to exist. Labels 
and peak colors are coordinated. Results for Mo 3d, Ti 2p, and $\mathrm{O}$ 1s regions are summarized in Tables 1, 2 and 3, respectively.

Table 1: XPS peak fitting results for Mo 3d region for ML- and $d$-films of $\mathrm{Mo}_{2} \mathrm{TiC}_{2} \mathrm{~T}_{\mathrm{z}}$ and $\mathrm{Mo}_{2} \mathrm{Ti}_{2} \mathrm{C}_{3} \mathrm{~T}_{\mathrm{z}}$.

\begin{tabular}{|c|c|c|c|c|c|}
\hline Sample & $\mathrm{BE}[\mathrm{eV}]^{\mathrm{a}}$ & FWHM $[\mathrm{eV}]^{\mathrm{a}}$ & Fraction & Assigned to & Reference \\
\hline $\mathrm{ML} \mathrm{Mo}_{2} \mathrm{TiC}_{2}$ & $\begin{array}{l}228.4(231.6) \\
229.6(232.8) \\
231.2(234.3) \\
232.6(235.7) \\
\end{array}$ & $\begin{array}{l}0.7(0.7) \\
1.0(1.3) \\
1.1(1.2) \\
1.1(1.9) \\
\end{array}$ & $\begin{array}{l}0.09 \\
0.79 \\
0.04 \\
0.08 \\
\end{array}$ & $\begin{array}{l}\mathrm{Mo}_{2} \mathrm{C} \text { bulk carbide } \\
\mathrm{C}-\mathrm{Mo}_{\mathrm{x}} \mathrm{T}_{\mathrm{x}} \\
\mathrm{Mo}^{+5} \\
\mathrm{Mo}^{+6}\end{array}$ & $\begin{array}{c}{[54]} \\
{[17,54]} \\
{[47]} \\
{[47]} \\
\end{array}$ \\
\hline$d-\mathrm{Mo}_{2} \mathrm{TiC}_{2}$ & $\begin{array}{l}229.4(232.6) \\
230.9(234.0) \\
232.4(235.5)\end{array}$ & $\begin{array}{l}0.8(1.1) \\
1.2(1.1) \\
1.2(2.0)\end{array}$ & $\begin{array}{l}0.88 \\
0.04 \\
0.08\end{array}$ & $\begin{array}{l}\text { C-Mo-T } \\
\mathrm{Mo}^{+5} \\
\mathrm{Mo}^{+6}\end{array}$ & $\begin{array}{c}{[17,54]} \\
{[55]} \\
{[47]}\end{array}$ \\
\hline $\mathrm{ML}-\mathrm{Mo}_{2} \mathrm{Ti}_{2} \mathrm{C}_{3}$ & $\begin{array}{l}229.3(232.5) \\
230.9(234.0) \\
232.5(235.6) \\
\end{array}$ & $\begin{array}{l}0.9(1.4) \\
1.0(1.0) \\
1.0(2.0) \\
\end{array}$ & $\begin{array}{l}0.86 \\
0.04 \\
0.10\end{array}$ & $\begin{array}{l}\text { C-Mo-T } \\
\mathrm{Mo}^{+5} \\
\mathrm{Mo}^{+6}\end{array}$ & $\begin{array}{c}{[17,54]} \\
{[47]} \\
{[47]}\end{array}$ \\
\hline$d-\mathrm{Mo}_{2} \mathrm{Ti}_{2} \mathrm{C}_{3}$ & $\begin{array}{l}229.6(232.8) \\
232.3(235.4) \\
\end{array}$ & $\begin{array}{l}0.7(0.8) \\
1.0(2.0) \\
\end{array}$ & $\begin{array}{l}0.92 \\
0.08 \\
\end{array}$ & $\begin{array}{l}\text { C-Mo-T } \\
\mathrm{Mo}^{+6} \\
\end{array}$ & $\begin{array}{c}{[17,54]} \\
{[47]} \\
\end{array}$ \\
\hline
\end{tabular}

${ }^{\text {a }}$ Values in parenthesis correspond to the $3 \mathrm{~d}_{5 / 2}$ component. In the fitting procedure, the areal ratio of the Mo $3 \mathrm{~d}_{5 / 2}$ and $3 \mathrm{~d}_{3 / 2}$ peaks were constrained to $3: 2$.

\section{Titanium}

High-resolution spectra in the Ti $2 p$ region for ML- (lower spectra) and $d$-21(upper spectra) films are shown in Fig. 2b. The corresponding results for 22 are shown in Fig. 2e. The fitting parameters are summarized in Table 2 . In all cases, at least four components for Ti-C, Ti (II), Ti (III), and $\mathrm{Ti}(\mathrm{IV}) / \mathrm{TiO}_{2}$ were used. The respective $\mathrm{BE}$ 's were $\approx 455 \mathrm{eV}, \approx 455.7 \mathrm{eV}, \approx 457.2 \mathrm{eV}$ and, $\approx 459 \mathrm{eV}$. Like in our previous work $[13,24]$, the first 3 contributions are assigned to Ti atoms in the MXene films. The fourth contribution, at a $\mathrm{BE}$ of $\approx 459 \mathrm{eV}$, was assigned to $\mathrm{TiO}_{2}[56]$. 
Table 2: XPS peak fitting results for Ti 2p region for ML- and $d$ - thin films of $\mathrm{Mo}_{2} \mathrm{TiC}_{2} \mathrm{~T}_{\mathrm{z}}$ and $\mathrm{Mo}_{2} \mathrm{Ti}_{2} \mathrm{C}_{3} \mathrm{~T}_{\mathrm{z}}$.

\begin{tabular}{|c|c|c|c|c|c|}
\hline Sample & $\mathrm{BE}[\mathrm{eV}]^{\mathrm{a}}$ & FWHM $[\mathrm{eV}]^{\mathrm{a}}$ & Fraction & Assigned to & Reference \\
\hline \multirow{4}{*}{$\begin{array}{l}\text { Cold pressed } \\
\text { multilayered } \\
\mathrm{Mo}_{2} \mathrm{TiC}_{2}\end{array}$} & $455.2(461.4)$ & $0.8(1.7)$ & 0.23 & Ti-C & {$[13,54]$} \\
\hline & $455.9(461.4)$ & $1.5(2.0)$ & 0.35 & $\mathrm{Ti}^{+2}-\mathrm{C}$ & {$[13,54]$} \\
\hline & $457.2(462.9)$ & $1.8(2.2)$ & 0.24 & $\mathrm{Ti}^{+3}-\mathrm{C}$ & {$[13,54]$} \\
\hline & $459.2(465.1)$ & $1.6(2.5)$ & 0.18 & $\mathrm{TiO}_{2}$ & {$[56]$} \\
\hline \multirow{4}{*}{$\begin{array}{l}\text { Delaminated } \\
\text { freestanding } \\
\mathrm{Mo}_{2} \mathrm{TiC}_{2}\end{array}$} & $455.3(461.6)$ & $0.9(1.8)$ & 0.20 & Ti-C & {$[13,54]$} \\
\hline & $456.0(461.7)$ & $1.4(2.2)$ & 0.22 & $\mathrm{Ti}^{+2}-\mathrm{C}$ & {$[13,54]$} \\
\hline & $457.4(463.1)$ & $1.9(2.5)$ & 0.13 & $\mathrm{Ti}^{+3}-\mathrm{C}$ & {$[13,54]$} \\
\hline & $459.3(464.9)$ & $1.4(2.2)$ & 0.45 & $\mathrm{TiO}_{2}$ & [56] \\
\hline \multirow{4}{*}{$\begin{array}{l}\text { Cold pressed } \\
\text { multilayered } \\
\mathrm{Mo}_{2} \mathrm{Ti}_{2} \mathrm{C}_{3} \\
\end{array}$} & $455.2(461.4)$ & $0.7(1.6)$ & 0.32 & Ti-C & {$[13,54]$} \\
\hline & $455.7(461.2)$ & $1.5(1.9)$ & 0.36 & $\mathrm{Ti}^{+2}-\mathrm{C}$ & {$[13,54]$} \\
\hline & $457.4(463.1)$ & $2.0(2.0)$ & 0.22 & $\mathrm{Ti}^{+3}-\mathrm{C}$ & {$[13,54]$} \\
\hline & $459.2(465.2)$ & $1.8(2.7)$ & 0.10 & $\mathrm{TiO}_{2}$ & [56] \\
\hline \multirow{4}{*}{$\begin{array}{l}\text { Delaminated } \\
\text { freestanding } \\
\mathrm{Mo}_{2} \mathrm{Ti}_{2} \mathrm{C}_{3}\end{array}$} & $455.2(461.4)$ & $0.8(1.8)$ & 0.48 & Ti-C & {$[13,54]$} \\
\hline & $455.9(461.4)$ & $1.3(1.8)$ & 0.10 & $\mathrm{Ti}^{+2}-\mathrm{C}$ & {$[13,54]$} \\
\hline & $457.2(462.9)$ & $2.0(2.0)$ & 0.10 & $\mathrm{Ti}^{+3}-\mathrm{C}$ & {$[13,54]$} \\
\hline & $459.2(464.8)$ & $1.9(2.5)$ & 0.32 & $\mathrm{TiO}_{2}$ & {$[56]$} \\
\hline
\end{tabular}

${ }^{a}$ Values in parenthesis correspond to the $2 \mathrm{p}_{1 / 2}$ component. The areal ratios of the Ti $2 \mathrm{p}_{3 / 2}$ and $2 \mathrm{p}_{1 / 2}$ peaks were constrained to $2: 1$. 

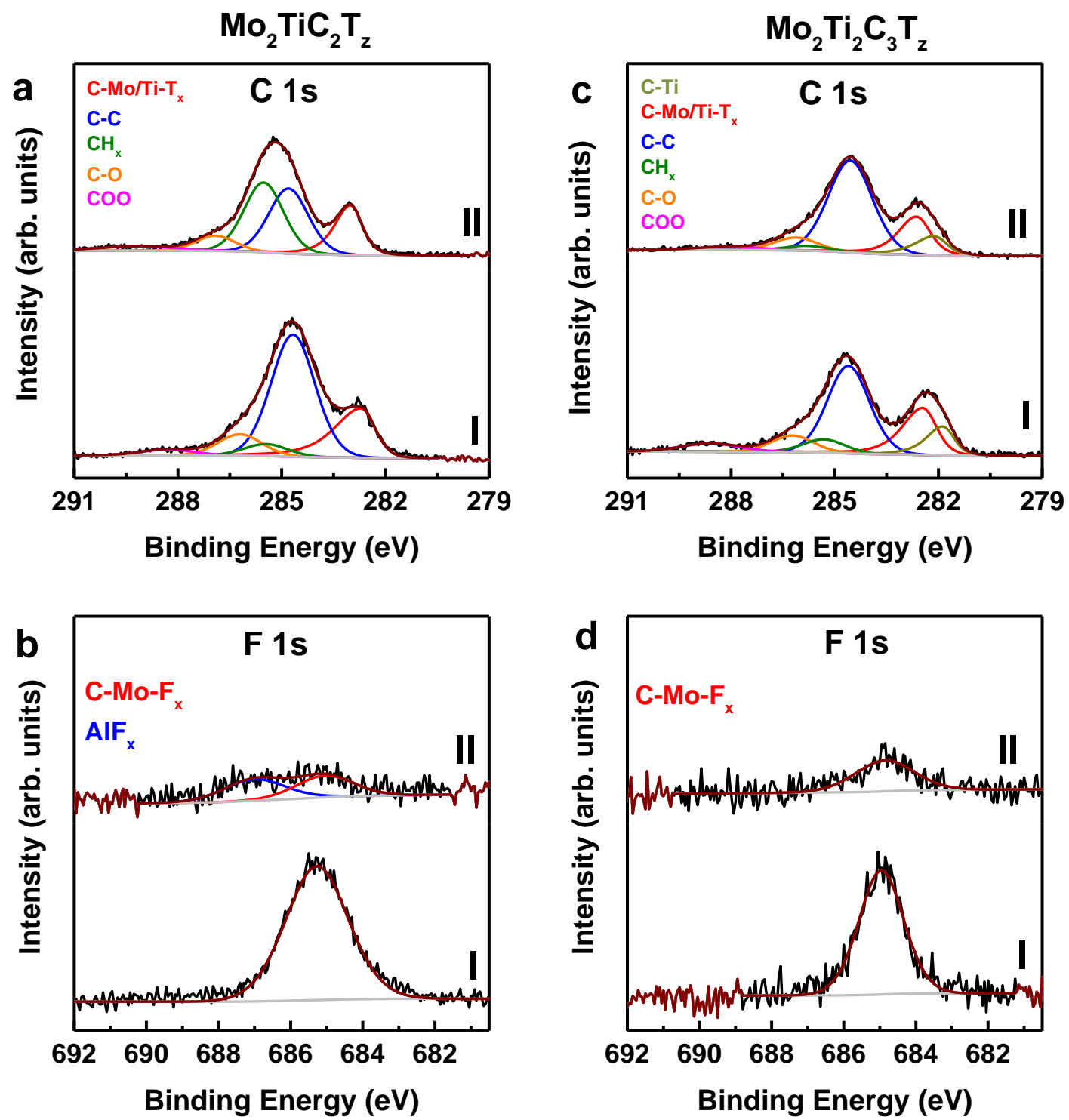

Figure 3: XPS spectra with curve fitting for: (a) C 1s, (b) F 1s regions for ML- (I) and $d$ - (II) thin film for 21, (c) same as (a) but for 22, d) same as (b) but for 22. Various peaks shown represent various species assumed to exist. Labels and peak colors are coordinated. The results for $\mathrm{C} 1 \mathrm{~s}$ and $\mathrm{F} 1 \mathrm{~s}$ regions are summarized in Tables $\mathrm{S} 1$ and $\mathrm{S} 2$, respectively.

\section{Oxygen}

In the $\mathrm{O}$ 1s region, the ML-21 (lower) and $d-21$ (upper) spectra (Fig. 2c) were fit by four components listed in Table 3. The corresponding spectra for the ML- (lower) and $d$-22 (upper) films were also fit by four components, (Fig. 2f), with BEs listed in Table 3. The fitted component of $\mathrm{BE} \approx 530 \mathrm{eV}$ corresponds to molybdenum oxides $\left(\mathrm{MoO}_{\mathrm{x}}\right), \mathrm{TiO}_{2}$ and/or oxygen surface terminations sitting on B or HCP sites (atom labeled $\mathrm{O}(\mathrm{I})$ in Fig. 1). These will henceforth be 
referred in the final composition as $\mathrm{O}(\mathrm{I})_{\mathrm{x}}$. The fitted components of $\mathrm{BE} \approx 531 \mathrm{eV}$, are assigned to $\mathrm{O}$ surface terminations on the A or FCC sites - (atom labeled O(II) in Fig. 1) and will be referred to in the final formulae as C-Mo-O(II) . The peaks at BEs of $\approx 532 \mathrm{eV}$ and $533 \mathrm{eV}$ are assigned to C-Mo- $(\mathrm{OH})_{\mathrm{x}}$ and adsorbed water, respectively. The results in this table are important in that they are instrumental in differentiating between the various terminations.

One of the difficulties of interpreting $\mathrm{O}$ spectra in MXenes in general, and in this work in particular, is the overlap of some of $\mathrm{O}$ hydrocarbon impurity peaks with those of the surface terminations. As discussed below, the extent/severity of the problem can be quantified by carrying out a global analysis of the phases/elements present.

Table 3: XPS peak fitting results for $\mathrm{O} 1 \mathrm{~s}$ region for ML- and $d$ - thin films of $\mathrm{Mo}_{2} \mathrm{TiC}_{2} \mathrm{~T}_{\mathrm{z}}$ and $\mathrm{Mo}_{2} \mathrm{Ti}_{2} \mathrm{C}_{3} \mathrm{~T}_{\mathrm{z}}$.

\begin{tabular}{|c|c|c|c|c|c|}
\hline Sample & $\mathrm{BE}[\mathrm{eV}]^{\mathrm{a}}$ & FWHM $[\mathrm{eV}]^{\mathrm{a}}$ & Fraction & Assigned to & Reference \\
\hline \multirow{4}{*}{$\mathrm{ML}-\mathrm{Mo}_{2} \mathrm{TiC}_{2}$} & 529.9 & $\overline{1.1}$ & 0.37 & 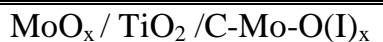 & [54] \\
\hline & 531.1 & 1.2 & 0.16 & $\mathrm{C}-\mathrm{Mo}-\mathrm{O}(\mathrm{III})_{\mathrm{x}}$ and/or $\mathrm{OR}^{\mathrm{b}}$ & [54] \\
\hline & 532.0 & 1.7 & 0.31 & C-Mo- $(\mathrm{OH})_{\mathrm{x}}$ and/or $\mathrm{OR}^{\mathrm{b}}$ & [54] \\
\hline & 533.1 & 1.9 & 0.16 & $\mathrm{H}_{2} \mathrm{O}_{\text {ads }}$ (IV) and/or $\mathrm{OR}^{\mathrm{b}}$ & [54] \\
\hline \multirow{4}{*}{$\mathrm{d}-\mathrm{Mo}_{2} \mathrm{TiC}_{2}$} & 530.0 & 1.1 & 0.25 & $\mathrm{MoO}_{\mathrm{x}} / \mathrm{TiO}_{2} / \mathrm{C}-\mathrm{Mo}-\mathrm{O}(\mathrm{I})$ & [54] \\
\hline & 531.0 & 1.1 & 0.12 & C-Mo-O(II $)_{\mathrm{x}}$ and/or $\mathrm{OR}^{\mathrm{b}}$ & [13] \\
\hline & 532.3 & 1.5 & 0.54 & C-Mo- $(\mathrm{OH})_{\mathrm{x}}$ and/or $\mathrm{OR}^{\mathrm{b}}$ & [13] \\
\hline & 533.3 & 2.0 & 0.09 & $\mathrm{H}_{2} \mathrm{O}_{\text {ads }}(\mathrm{IV})$ and/or $\mathrm{OR}^{\mathrm{b}}$ & [13] \\
\hline \multirow{4}{*}{$\mathrm{ML}-\mathrm{Mo}_{2} \mathrm{Ti}_{2} \mathrm{C}_{3}$} & 530.0 & 1.2 & 0.45 & $\mathrm{MoO}_{\mathrm{x}} / \mathrm{TiO}_{2} / \mathrm{C}-\mathrm{Mo}-\mathrm{O}(\mathrm{I})$ & [54] \\
\hline & 530.9 & 1.3 & 0.16 & C-Mo-O(II $)_{x}$ and/or $\mathrm{OR}^{\mathrm{b}}$ & [54] \\
\hline & 531.9 & 1.7 & 0.33 & C-Mo- $(\mathrm{OH})_{\mathrm{x}}$ and/or $\mathrm{OR}^{\mathrm{b}}$ & [54] \\
\hline & 533.0 & 1.8 & 0.06 & $\mathrm{H}_{2} \mathrm{O}_{\text {ads }}$ and/or $\mathrm{OR}^{\mathrm{b}}$ & [54] \\
\hline \multirow{4}{*}{$\mathrm{d}-\mathrm{Mo}_{2} \mathrm{Ti}_{2} \mathrm{C}_{3}$} & 530.0 & 1.2 & 0.35 & $\mathrm{MoO}_{\mathrm{x}} / \mathrm{TiO}_{2} / \mathrm{C}-\mathrm{Mo}-\mathrm{O}(\mathrm{I})$ & [54] \\
\hline & 531.0 & 1.6 & 0.28 & C-Mo-O(II $)_{\mathrm{x}}$ and/or $\mathrm{OR}^{\mathrm{b}}$ & [13] \\
\hline & 531.9 & 1.7 & 0.28 & C-Mo- $(\mathrm{OH})_{\mathrm{x}}$ and/or $\mathrm{OR}^{\mathrm{b}}$ & [13] \\
\hline & 533.3 & 1.8 & 0.09 & $\mathrm{H}_{2} \mathrm{O}_{\text {ads }}$ and/or $\mathrm{OR}^{\mathrm{b}}$ & [13] \\
\hline
\end{tabular}

${ }^{a}$ Values in parenthesis correspond to the $2 \mathrm{p}_{1 / 2}$ component.

${ }^{\mathrm{b}}$ OR stands for organic contamination.

\section{Carbon}

High-resolution XPS spectra in the C 1s region for ML-21 (lower spectra) and $d$-21 (upper spectra) films, shown in Fig. 3a, were fit by five components listed in Table S1. The C spectra for ML-22 (lower) and $d$-22 (upper) films (Fig. 3c) were fit by six components also listed in Table S1.

The first component, at a $\mathrm{BE}$ of $\approx 282.5 \mathrm{eV}$ - labelled C-Mo/Ti-T $\mathrm{x}$ in Table $\mathrm{S} 1$ - corresponds to $\mathrm{C}$ atoms bonded to both Mo and Ti atoms and exists in both compositions. This binding energy is the same as the one for $\mathrm{C}$ in the parent MAX phases [36]. The peak at $\mathrm{BE}$ of $\approx 282 \mathrm{eV}$, only present in the $\mathrm{Mo}_{2} \mathrm{Ti}_{2} \mathrm{C}_{3} \mathrm{~T}_{\mathrm{Z}}$ composition is ascribed to $\mathrm{C}$ atoms bound only to Ti atoms, i.e. $\mathrm{C}$ atoms in the center of the Mo-Ti-Ti-Mo block (Fig. 1).

For the ML-21 samples, the largest - $57 \%$ - component, is graphitic carbon (C-C), while carbon contamination $\left(\mathrm{CH}_{\mathrm{x}}, \mathrm{C}-\mathrm{O}\right.$, and $\left.\mathrm{COO}\right)$ each made small contributions. Graphitic carbon is a 
well-known byproduct of MXene synthesis [13]. The C-contamination is deposited adventitiously from the surroundings. After delamination, the same five species are present, albeit in different ratios. The amount of graphitic carbon decreases, to 33\%, while the amount of hydrocarbon contamination increases to $35 \%$. The $\mathrm{BE}$ of the $\mathrm{C}-\mathrm{Mo} / \mathrm{Ti}-\mathrm{T}_{\mathrm{x}}$ component shifted higher by $\approx 0.5$ $\mathrm{eV}$, after delamination, which again correlates to an increase in overall oxidation state.

The largest component, for both ML- and $d-22$ was again was graphitic carbon $(\mathrm{C}-\mathrm{C}, 46 \%$ and $57 \%$, respectively), while carbon contamination $\left(\mathrm{CH}_{\mathrm{x}}, \mathrm{C}-\mathrm{O}\right.$, and $\left.\mathrm{COO}\right)$ again made small contributions. Interestingly, after delamination the amount of graphitic carbon increased, rather than decreased as was the case with $\mathrm{Mo}_{2} \mathrm{TiC}_{2} \mathrm{~T}_{\mathrm{z}}$, while the amount of hydrocarbon contamination decreased.

\section{Fluorine}

High-resolution XPS spectra in the F 1s region for ML-21 (lower spectra) and $d$-21(upper spectra) films, shown in Fig. 3b, were fit by the components listed in Table S2. The F spectra for ML-22 (lower) and $d$-22 (upper) films (Fig. 2d) were fit by components also listed in Table S2. Of all fits, the least ambiguous are those of $\mathrm{F}$. With the exception of the $d-21$ sample - where an additional peak at $687.0 \mathrm{eV}$ ascribed to $\mathrm{Al}(\mathrm{OF})_{\mathrm{x}}$ was needed - all other spectra were fitted by only one peak at a $\mathrm{BE}$ of $\approx 684$ to $685 \mathrm{eV}$, ascribed to F-terminations, viz. C-Mo-F (see Fig.1).

\section{Chemical formulae of $\mathrm{Mo}_{2} \mathrm{TiC}_{2} \mathrm{~T}_{z}$ and $\mathrm{Mo}_{2} \mathrm{Ti}_{2} \mathrm{C}_{3} \mathrm{~T}_{z}$}

Table 4 lists the chemical formulae of ML and d-thin films of 21 and 22 as determined from the XPS spectra. The moles of each surface group per chemical formula unit, f.u., is represented graphically in Fig. 4a. To arrive at these values a number of assumptions were made. First and foremost, we assume the Mo atomic sites to be fully occupied, viz. 2 atoms per f.u. If that assumption is not made it is difficult, if not impossible, to quantify the terminations. A perusal of Fig. 4a makes it is clear than in 3 out of 4 cases, $z>2$. However, since DFT calculations have shown that for $z>2$, the energy of the MXene flakes increases rapidly, this is unlikely [57]. How this problem is solved is discussed below.

Lastly, the total $\mathrm{O}$ content is the sum of $\mathrm{O}$ associated with: i) terminations, ii) the oxides, $\mathrm{MoO}_{3}$, $\mathrm{Mo}_{2} \mathrm{O}_{5}$ and $\mathrm{TiO}_{2}$ and, iii) those occupying $\mathrm{C}$-vacancies. As discussed below, the latter is needed to reduce $\mathrm{z}$ to $\approx 2$ and has been shown to occur in reduced $\mathrm{Ti}_{3} \mathrm{C}_{2} \mathrm{~T}_{\mathrm{z}}$ [58]. 

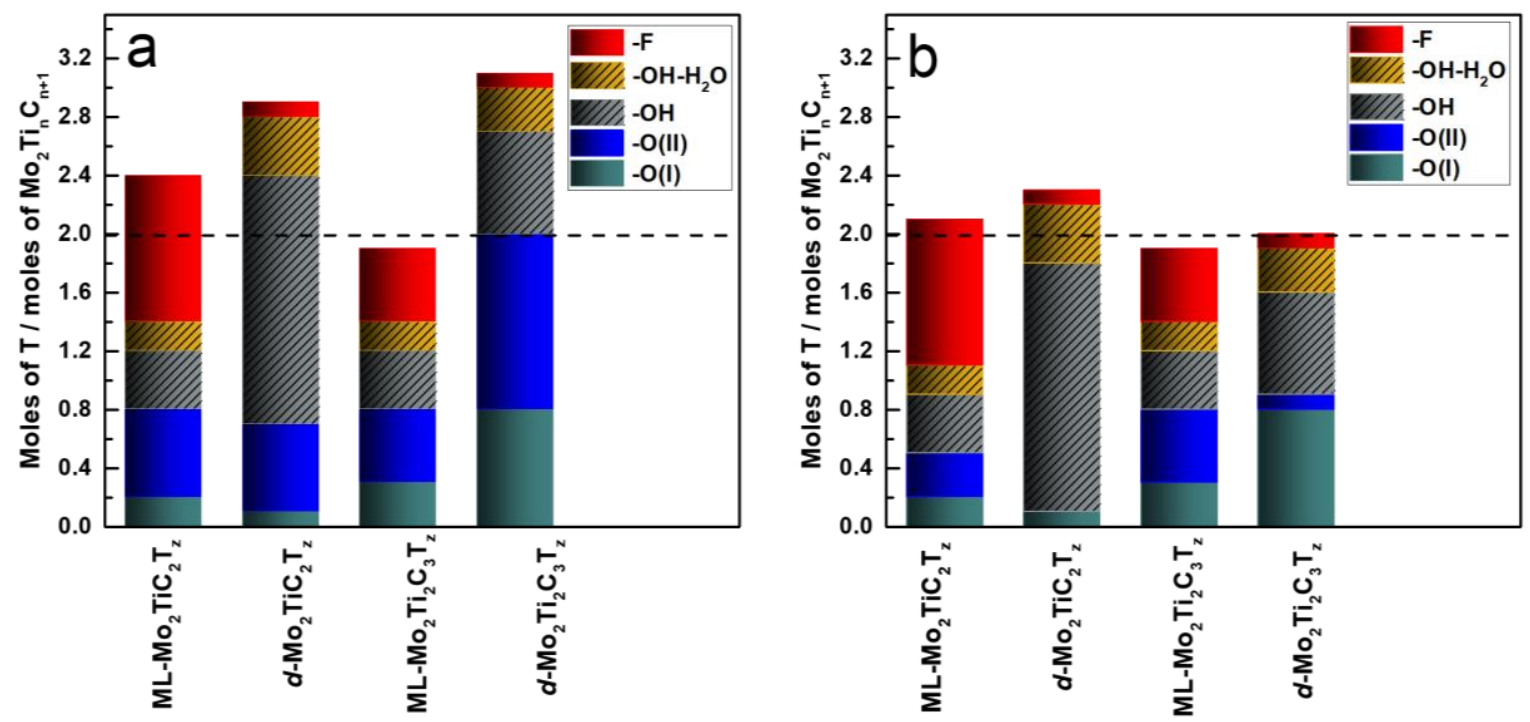

Figure 4: Moles of surface terminations, $\mathrm{T}$, per $\mathrm{Mo}_{2} \mathrm{Ti}_{n} \mathrm{C}_{\mathrm{n}+1}$ for the chemistries listed in Table 4 assuming, a) no $\mathrm{O}$ atoms reside on $\mathrm{C}$-vacant sites, and b) some of the $\mathrm{O}$ atoms reside on the $\mathrm{C}$ vacant sites. Note that if one termination is assumed per surface $M$ atom, then the number of terminations per formula is 2 , which is given by the horizontal dashed line.

If the $\mathrm{M} / \mathrm{C}$ ratio is near stoichiometric, then the oxides are separate phases and their $\mathrm{O}$ content simply needs to be subtracted from the total $\mathrm{O}$. If the $\mathrm{M} / \mathrm{C}$ ratio is < stoichiometric then the probability exists that some of the $\mathrm{O}$ atoms occupy the $\mathrm{C}$-vacancies. How to differentiate between these is discussed next. First, the fractions of $\mathrm{Mo}^{+5}$ and $\mathrm{Mo}^{6+}$ are determined and their oxygen $\left(\mathrm{MoO}_{3}\right.$ and $\left.\mathrm{Mo}_{2} \mathrm{O}_{5}\right)$ at $\mathrm{BE}$ of $530 \mathrm{eV}$ are calculated and subtracted from the total. Once that $\mathrm{O}$ is subtracted, then the remaining $\mathrm{O}$ was identified as either $\mathrm{O}(\mathrm{I})$ or $\mathrm{O}(\mathrm{II})$ as discussed above [42]. The results obtained using this approach are listed in the un-highlighted rows in Table 4.

Since DFT calculations have shown that the energy of the system increases considerably when $\mathrm{z}$ is $>2$, three of the entries are problematic since $\mathrm{z}>2$. Furthermore, in a recent paper [58], we presented evidence for the substitution of $\mathrm{O}$ onto $\mathrm{C}$ vacant sites in reduced $\mathrm{Ti}_{3} \mathrm{C}_{2} \mathrm{~T}_{\mathrm{z}}$. If we assume that the same is happening here, then we can partially explain the fact that $\mathrm{z}>2$ as follows.

For ML-21, we can place 0.3 moles of the $\mathrm{O}$ in the $\mathrm{C}$ vacancies. These oxygens will be referred to as $\mathrm{O}$ (III) and are subtracted from O(II). Said otherwise, we assume that we cannot distinguish between $\mathrm{O}$ (II) and $\mathrm{O}$ (III) via fitting the XPS spectra. The final chemistry is thus given in the highlighted second row. The advantage of this approach is that now $\mathrm{z}=2.1$ which is more reasonable. The location of these $\mathrm{O}$ atoms is shown schematically in Fig. 1 as $\mathrm{O}$ (III).

In the $\mathrm{d}-21$ case, before correction, $\mathrm{z}=2$.9. If we now reassign 0.6 moles of $\mathrm{O}$ (II) to $\mathrm{O}$ (III), $\mathrm{z}$ drops to 2.3, which is slightly higher than 2, but lower than 2.9. Why $\mathrm{z}$ is not 2 is unclear at this time. The final chemistry is given in highlighted row 4 of Table 4 . Note in this case, the sum of $\mathrm{C}$ and $\mathrm{O}$ (III) is exactly equal to 2 , which is the number of $\mathrm{C}$ sites per formula unit. 
In the ML-22 case, $\mathrm{z} \approx 2$ and thus there is no reason to assume that any of the $\mathrm{C}$ sites are occupied by $\mathrm{O}$ and no further corrections are needed.

For the $\mathrm{d}-22$ composition, $\mathrm{z}=3.1$, however, the $\mathrm{C}$-content after etching is also quite low. If, as done above, one now reassigns 1.1 moles of $\mathrm{O}(\mathrm{II})$ to $\mathrm{O}$ (III), $\mathrm{z}$ equals 2 . The resulting chemistry is shown in the last highlighted row. In this case, the sum of the remaining $\mathrm{C}$ and $\mathrm{O}$ (III) is equal to 2.5, which is the starting $\mathrm{C}$ content.

Lastly, we note that the starting MAX compositions, as determined by XPS, were found to be $\mathrm{Mo}_{2} \mathrm{TiAlC}_{1.7}$ and $\mathrm{Mo}_{2} \mathrm{Ti}_{1.9} \mathrm{Al}_{0.9} \mathrm{C}_{2.5}$, respectively [36]. It follows that both starting compositions were C-deficient. The latter is also slightly Ti deficient.

Table 4: Chemical formulae of ML- and $d$ - thin films of 21 and 22 compositions determined from XPS spectra. Also listed are the chemistries of the parent MAX phases determined by XPS in Ref. [36]. The highlighted entries assume that some of the $\mathrm{O}$ atoms reside on $\mathrm{C}$-sites.

\begin{tabular}{|c|c|}
\hline Parent phase $\left(\mathrm{Mo}_{2} \mathrm{TiAlC}_{2}\right)$ & $\mathrm{Mo}_{2} \mathrm{TiAlC}_{1.7}$ \\
\hline \multirow[t]{2}{*}{$\mathrm{ML}-\mathrm{Mo}_{2} \mathrm{TiC}_{2} \mathrm{~T}_{\mathrm{z}}$} & $\begin{array}{l}\mathrm{Mo}_{2} \mathrm{Ti}_{0.8} \mathrm{C}_{1.7} \mathrm{O}(\mathrm{I})_{0.2} \mathrm{O}(\mathrm{II})_{0.6}(\mathrm{OH})_{0.6} \mathrm{~F}_{1.0} \cdot 0.2 \mathrm{H}_{2} \mathrm{O}_{\text {ads. }} \\
\mathrm{z}=2.4\end{array}$ \\
\hline & $\begin{array}{l}\mathrm{Mo}_{2} \mathrm{Ti}_{0.8} \mathrm{C}_{1.7} \mathrm{O}(\mathrm{III})_{0.3} \mathrm{O}(\mathrm{I})_{0.2} \mathrm{O}(\mathrm{II})_{0.3}(\mathrm{OH})_{0.6} \mathrm{~F}_{1.0} \cdot 0.2 \mathrm{H}_{2} \mathrm{O} \text { ads. } \\
\mathrm{z}=2.1\end{array}$ \\
\hline \multirow[t]{2}{*}{$d-\mathrm{Mo}_{2} \mathrm{TiC}_{2} \mathrm{~T}_{\mathrm{z}}$} & $\begin{array}{l}\mathrm{Mo}_{2} \mathrm{Ti}_{0.6} \mathrm{C}_{1.2} \mathrm{O}(\mathrm{I})_{0.1} \mathrm{O}(\mathrm{II})_{0.6}(\mathrm{OH})_{2.1} \mathrm{~F}_{0.1} \cdot 0.4 \mathrm{H}_{2} \mathrm{O}_{\text {ads. }} \\
\mathrm{z}=2.9\end{array}$ \\
\hline & $\begin{array}{l}\mathrm{Mo}_{2} \mathrm{Ti}_{0.6} \mathrm{C}_{1.2} \mathrm{O}(\mathrm{III})_{0.6} \mathrm{O}(\mathrm{I})_{0.1}(\mathrm{OH})_{2.1} \mathrm{~F}_{0.1} \cdot 0.4 \mathrm{H}_{2} \mathrm{O}_{\text {ads. }} \\
\mathrm{z}=2.3\end{array}$ \\
\hline Parent phase $\left(\mathrm{Mo}_{2} \mathrm{Ti}_{2} \mathrm{AlC}_{3}\right)$ & $\mathrm{Mo}_{2} \mathrm{Ti}_{1.9} \mathrm{Al}_{0.9} \mathrm{C}_{2.5}$ \\
\hline $\mathrm{ML}-\mathrm{Mo}_{2} \mathrm{Ti}_{2} \mathrm{C}_{3} \mathrm{~T}_{\mathrm{z}}$ & $\begin{array}{l}\mathrm{Mo}_{2} \mathrm{Ti}_{1.3} \mathrm{C}_{2.2} \mathrm{O}(\mathrm{I})_{0.3} \mathrm{O}(\mathrm{II})_{0.5}(\mathrm{OH})_{0.6} \mathrm{~F}_{0.5} \cdot 0.2 \mathrm{H}_{2} \mathrm{O}_{\text {ads. }} \\
\mathrm{z}=1.9\end{array}$ \\
\hline \multirow[t]{2}{*}{$d-\mathrm{Mo}_{2} \mathrm{Ti}_{2} \mathrm{C}_{3} \mathrm{~T}_{\mathrm{z}}$} & $\begin{array}{l}\mathrm{Mo}_{2} \mathrm{Ti}_{1.1} \mathrm{C}_{1.6} \mathrm{O}(\mathrm{I})_{0.8} \mathrm{O}(\mathrm{II})_{1.2}(\mathrm{OH})_{1.0} \mathrm{~F}_{0.1} \cdot 0.3 \mathrm{H}_{2} \mathrm{O}_{\text {ads. }} \\
\mathrm{z}=3.1\end{array}$ \\
\hline & $\begin{array}{l}\mathrm{Mo}_{2} \mathrm{Ti}_{1.1} \mathrm{C}_{1.6} \mathrm{O}(\mathrm{III})_{1.1} \mathrm{O}(\mathrm{I})_{0.8} \mathrm{O}(\mathrm{II})_{0.1}(\mathrm{OH})_{1.0} \mathrm{~F}_{0.1} \cdot 0.3 \mathrm{H}_{2} \mathrm{O}_{\text {ads. }} \\
\mathrm{z}=2.0\end{array}$ \\
\hline
\end{tabular}

$\mathrm{O}(\mathrm{I})$ is $\mathrm{O}$ surface termination occupying the HCP site [42].

$\mathrm{O}(\mathrm{II})$ is $\mathrm{O}$ surface termination occupying FCC site [42].

$\mathrm{O}(\mathrm{III})$ is $\mathrm{O}$ occupying a $\mathrm{C}$ vacancy site, assumed to reside between the $\mathrm{Ti}$ and Mo layers, viz. outer layers. The $\mathrm{O}(\mathrm{I}), \mathrm{O}(\mathrm{II})$, and $\mathrm{O}$ (III) moieties are shown schematically in Figs. 1a and b.

Table 5 lists the molar fractions of surface oxides and MXene in the various samples. From these results is it quite obvious that the harsh etching procedure needed to produce these MXene also leads to the dissolution of some of the Ti atoms and considerable oxidation. The least oxidized sample, ML-22, was only $70 \%$ MXene; the most oxidized, d-21, was only $59 \%$. 
Lastly, to double check the validity of our results, we compared the global atomic ratios of the transition metals and oxygen contents as calculated from the molar percentage of the various compounds shown in Table 5 to those of the global atomic ratios measured by XPS (listed in Table $\mathrm{S} 3$ ). There were no discrepancies for the transition metal content. However, for the $\mathrm{O}$ content, the ML-21, $d$-21, ML-22 and $d$-22 films, were 10\%, 3\%, 10\% and 7\% off, respectively. Note that the ML-22 was the least oxidized sample.

Table 5: Global molar percentages of MXene, $\mathrm{Mo}_{2} \mathrm{C}$, and surface oxides of ML- and $d$-films of 21 and 22 MXenes.

\begin{tabular}{|l|l|l|l|l|l|}
\hline Sample & MXene & $\mathrm{Mo}_{2} \mathrm{C}$ & $\mathrm{TiO}_{2}$ & $\mathrm{Mo}_{2} \mathrm{O}_{5}$ & $\mathrm{MoO}_{3}$ \\
\hline ML-Mo $\mathrm{TiC}_{2} \mathrm{~T}_{\mathrm{z}}$ & 67.0 & 5.3 & 10.5 & 3.5 & 13.7 \\
\hline$d-\mathrm{Mo}_{2} \mathrm{TiC}_{2} \mathrm{~T}_{\mathrm{z}}$ & 59.0 & & 28.0 & 2.7 & 10.3 \\
\hline $\mathrm{ML}_{2} \mathrm{Mo}_{2} \mathrm{Ti}_{2} \mathrm{C}_{3} \mathrm{~T}_{\mathrm{z}}$ & 70.3 & & 10.3 & 3.4 & 16.1 \\
\hline$d-\mathrm{Mo}_{2} \mathrm{Ti}_{2} \mathrm{C}_{3} \mathrm{~T}_{\mathrm{z}}$ & 62.4 & & 26.4 & & 11.2 \\
\hline
\end{tabular}

\section{Discussion}

Since the main purpose of this work was to quantify the terminations and shed some light on their distribution. The results shown in Table 4 are of paramount importance. The ultimate question, however, is how reasonable are these results? In this section we critically asses the chemical formulae obtained.

We start with results that are valid regardless of whether $\mathrm{O}$ occupies the vacant $\mathrm{C}$ sites or not:

a) Compared to their ML counterparts, the relative amounts of $-\mathrm{O}$ and $-\mathrm{OH}$ surface groups increase upon delamination, while the amounts of $-\mathrm{F}$ and $\mathrm{H}_{2} \mathrm{O}_{\text {ads }}$ surface groups decrease. This is not too surprising since $\mathrm{TBAOH}$ is known to reduce the concentration of the less stable $-\mathrm{F}$ terminations and replace them by $\mathrm{O}[17]$.

b) About 30 at. $\%$ of the MXene is oxidized during etching of the MLs. Delamination results in about $10 \%$ more oxidation (Table 5).

c) All starting MAX compositions are C-deficient. In three of four cases, the deficiency increases upon etching. In the ML-21 case, the $\mathrm{C}$ concentration does not change after etching.

d) Similarly, in all cases the Ti to Mo ratio decreases with etching. The Ti deficiency increases with etching and the deficiency is higher in delaminated than in the ML samples (Table 4).

Since in both 21 and 22 compositions, the Ti atoms are "buried" in the center of the M-X blocks, this last conclusion seems at first glance to be untenable. The way out of this apparent paradox is to realize that the ordering in these quaternary MAX phases is not perfect. In Ref.[36], 
we showed that $\approx 25 \%$ and $23 \%$ of the Ti atoms actually occupy Mo sites in the 21 and 22 MAX phases, respectively. It is for this reason that $25 \%$ of the atoms in the outer layers are labelled Ti in Fig. 1.

Given that, in concentrated HF, Ti is significantly more etchable than Mo, it is reasonable to conclude that the $\mathrm{Ti}$ atoms residing on Mo sites - i.e. those on the outer surfaces - are the first to dissolve. Note that if $\mathrm{Ti}_{3} \mathrm{C}_{2} \mathrm{~T}_{\mathrm{Z}}$ is allowed to remain as long as $168 \mathrm{~h}$ in $49 \% \mathrm{HF}$, it simply dissolves away [59]. Along the same lines, since the Ti content is not totally decimated after the harsh etching, it is reasonable to assume that the $\mathrm{Ti}$ in the inner layers either does not dissolve, or dissolves much more slowly. Note that another mechanism by which the Ti atoms can be selectively etched is from the flake edges which we conjecture is the ultimate source of the oxides that form (Table 5).

We note in passing that when the concentrations of Mo and Ti were measured by EDS in our previous work, it was concluded that the Mo:Ti ratio did not change after etching [14]. This work shows that not to be the case and which not surprisingly implies that using EDS to determine atomic ratios can lead to erroneous conclusions. XPS is much more sensitive and should be the preferred method.

Once the outer $\mathrm{Ti}$ atoms dissolve, it is further reasonable to assume that the $\mathrm{C}$ atoms attached to them also "dissolve". If that is the case, then: i) a correlation should exist between the Ti- and C-deficiencies as observed (Fig. 5a) and, ii) the deficiency should be larger in the delaminated samples than the ML ones, which is also observed (Fig. 5a). The important correlation between Ti and $\mathrm{C}$ concentration is also seen in Fig. 5b, where the Ti and $\mathrm{C}$ stoichiometries of the MAX and MXenes are plotted versus each other.

If indeed the trends seen in Fig. 5, are valid, then one has to conclude that the fraction of Ti atoms in the outer Mo layers was, before etching, greater in the 413 (22) than in the 312 (21) MAX phases. This is fully consistent with our previous work where we showed using DFT calculations that were corroborated by experimental results, that indeed disorder, especially Ti on Mo sites, is more likely in the 413 than in the 312 phase [36]. We note that useful insights unto the degree of disorder can possibly be obtained by quantifying, for example weight loss after etching with an etching solution that selectively etches Ti atoms as done here.

We give two arguments that some of the $\mathrm{O}$ atoms are not terminations, but reside on $\mathrm{C}$ sites, viz. those labeled $\mathrm{O}$ (III) in Table 4 and Fig. 1: i) DFT calculations that have shown that for $\mathrm{z}>2$, the energy of the system goes up significantly [57] and, ii) The fact that after filling all the $\mathrm{C}$ vacancies, $\mathrm{z}$ drops to $\approx 2$. This result is gratifying and shows that the assumption has some merit. Note that there is no other reasonable assumption for why $z>2$. As a matter of course, at this stage we can argue that if $\mathrm{z}>2$, then some of the $\mathrm{O}$ is most probably embedded in the MXene blocks, an important conclusion and consistent with recent work on reduced MXenes [58]. We note in passing that the most likely reason, for the substitution of $\mathrm{O}$ with $\mathrm{C}$ is a reduction in the overall energy of the system. DFT calculations confirming this important conclusion are needed at this juncture. Along the same lines it is well established in the TiC literature that Ti-oxycarbides exist and therefore this assumption is not too far-fetched. 
We now return to the fundamental assumption made to obtain the results listed in Table 4, viz. that the Mo sites in the MXene compositions are fully occupied. The simplest rationale is that if after the dissolution of Ti that occurs first - the Mo atoms were also to dissolve, then the structure would no longer be tenable and would simply dissolve. That explains the relatively higher oxide fractions after etching (Table 5).
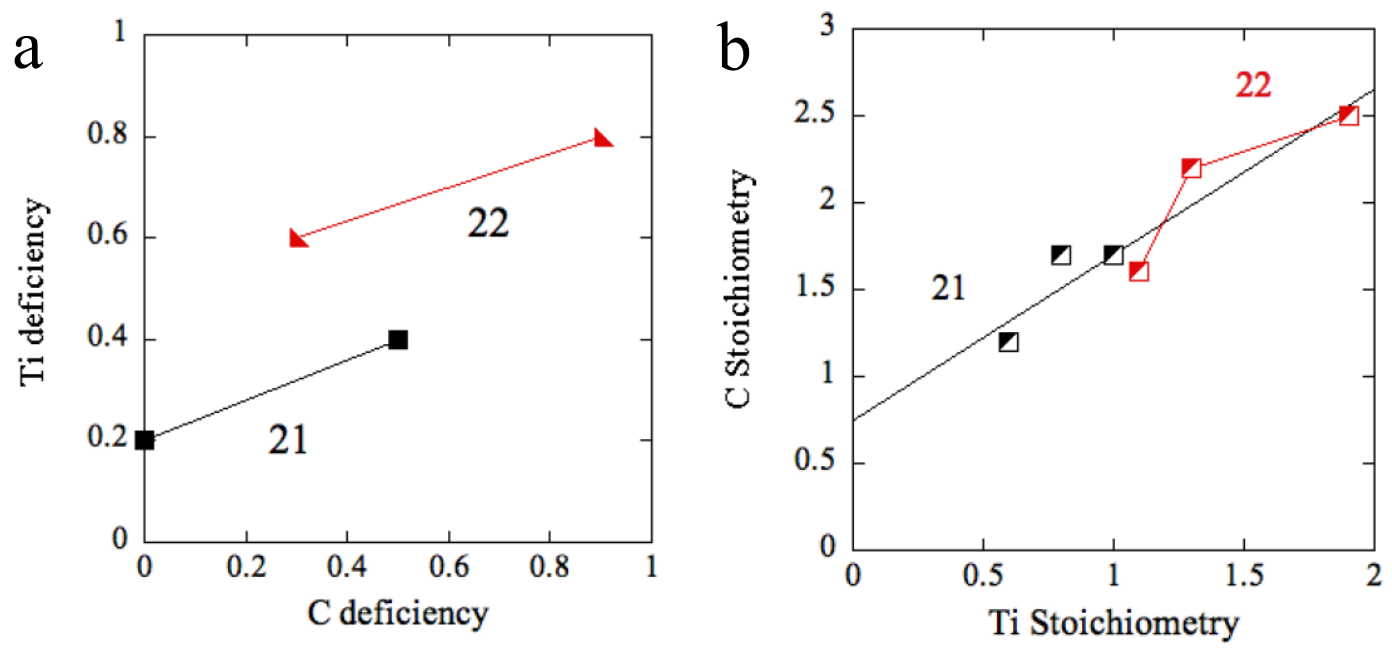

Figure 5: a. Correlation between $\mathrm{Ti}$ and $\mathrm{C}$ deficiencies per mole of MXene. The reported deficiency is relative to that of the initial parent MAX phase. b. Plot of Ti and C stoichiometries of MAX and MXenes studied herein. The numbers 21 and 22 stand for $\mathrm{Mo}_{2} \mathrm{TiAlC}_{2}(\mathrm{MAX})$, $\mathrm{Mo}_{2} \mathrm{TiC}_{2} \mathrm{~T}_{\mathrm{Z}}$ (MXene) and $\mathrm{Mo}_{2} \mathrm{Ti}_{2} \mathrm{AlC}_{3}(\mathrm{MAX}), \mathrm{Mo}_{2} \mathrm{Ti}_{2} \mathrm{C}_{3} \mathrm{~T}_{\mathrm{Z}}$ (MXene), respectively.

As alluded to in the introduction, DFT calculations predict that the electronic properties of MXenes are strongly dependent on the nature of the terminations. For example, it has been predicted that changing the nature of the terminations in $\mathrm{Mo}_{2} \mathrm{TiC}_{2} \mathrm{~T}_{\mathrm{Z}}$ and $\mathrm{Mo}_{2} \mathrm{Ti}_{2} \mathrm{C}_{3} \mathrm{~T}_{\mathrm{Z}}$ can introduce a small band gap. This prediction was used to explain why the conductivity of $\mathrm{Ti}_{3} \mathrm{C}_{2} \mathrm{~T}_{\mathrm{z}}$ was metallic whereas that in $\mathrm{Mo}_{2} \mathrm{TiC}_{2} \mathrm{~T}_{\mathrm{z}}$ and $\mathrm{Mo}_{2} \mathrm{Ti}_{2} \mathrm{C}_{3} \mathrm{~T}_{\mathrm{z}}$ was "semiconductor-like". Subsequent work on electron transport in $\mathrm{Mo}_{2} \mathrm{TiC}_{2} \mathrm{~T}_{\mathrm{Z}}$ and $\mathrm{Mo}_{2} \mathrm{Ti}_{2} \mathrm{C}_{3} \mathrm{~T}_{\mathrm{Z}}$ has shown that the reason for the weak increase in resistance with decreasing temperatures is not due to a band gap but rather due to variable range hopping, VRH, between flakes[37]. In the same work, we showed that for the same material the conductivity was a strong function of interlayer distance. In the VRH model the relationship between DOS and conductivity is anything but straightforward. The results obtained in this work, however, should be important in other applications such as catalysis and sensing. 


\section{Conclusions}

In summary, the composition and surface terminations of the MXenes $\mathrm{Mo}_{2} \mathrm{TiC}_{2} \mathrm{~T}_{\mathrm{z}}$ and $\mathrm{Mo}_{2} \mathrm{Ti}_{2} \mathrm{C}_{3} \mathrm{~T}_{\mathrm{Z}}$ in both the multilayered and delaminated states were determined from XPS spectra. The chemical formulae were determined to be $\mathrm{Mo}_{2} \mathrm{Ti}_{0.8} \mathrm{C}_{2} \mathrm{O}_{0.4}(\mathrm{OH})_{0.7} \mathrm{~F}_{1.0}-0.5 \mathrm{H}_{2} \mathrm{O}_{\text {ads }}$ and $\mathrm{Mo}_{2} \mathrm{Ti}_{1.5} \mathrm{C}_{2.5} \mathrm{O}_{0.6}(\mathrm{OH})_{1.0} \mathrm{~F}_{0.5}-0.5 \mathrm{H}_{2} \mathrm{O}_{\text {ads }}$ for the $\mathrm{ML}$ samples and $\mathrm{Mo}_{2} \mathrm{Ti}_{0.6} \mathrm{C}_{1.2} \mathrm{O}_{1.0}(\mathrm{OH})_{2.2} \mathrm{~F}_{0.05}-$ $0.3 \mathrm{H}_{2} \mathrm{O}_{\text {ads }}$, and $\mathrm{Mo}_{2} \mathrm{Ti}_{1.2} \mathrm{C}_{1.6} \mathrm{O}_{1.4}(\mathrm{OH})_{1.4} \mathrm{~F}_{0.1}-0.4 \mathrm{H}_{2} \mathrm{O}_{\text {ads }}$ for the $d$-samples if one assumes the $\mathrm{C}$ vacancies are unoccupied.

However, for these formulae, and with the exception of the ML-22 composition, $\mathrm{z}$ was found to be $>2$. Since DFT calculations have shown that to be unlikely, we postulate that some of the $\mathrm{O}$ atoms are not terminations, but rather sitting on $\mathrm{C}$ vacant sites that develop when the $\mathrm{Ti}$ atoms in the outer dissolve. These oxygens - labeled O(III) - are thus not termination and the 21 chemistries for the $\mathrm{ML}$ and $d$ - flakes are, respectively $\mathrm{Mo}_{2} \mathrm{Ti}_{0.8} \mathrm{C}_{1.7} \mathrm{O}(\mathrm{III})_{0.3} \mathrm{O}(\mathrm{I})_{0.2} \mathrm{O}(\mathrm{II})_{0.6}(\mathrm{OH})_{0.6} \mathrm{~F}_{1.0} \cdot 0.2 \mathrm{H}_{2} \mathrm{O}_{\text {ads }}$ with $\mathrm{z}=2.1$, and $\mathrm{Mo}_{2} \mathrm{Ti}_{0.6} \mathrm{C}_{1.2} \mathrm{O}(\mathrm{III})_{0.6} \mathrm{O}(\mathrm{I})_{0.1}(\mathrm{OH})_{2.1} \mathrm{~F}_{0.1} \cdot 0.4 \mathrm{H}_{2} \mathrm{O}_{\text {ads }}$, with $\mathrm{z}=2.3$.

The 22 chemistries for the ML and $d$ - flakes are, respectively, $\mathrm{Mo}_{2} \mathrm{Ti}_{1.3} \mathrm{C}_{2.2} \mathrm{O}(\mathrm{I})_{0.3} \mathrm{O}(\mathrm{II})_{0.5}(\mathrm{OH})_{0.6} \mathrm{~F}_{0.5} \cdot 0.2 \mathrm{H}_{2} \mathrm{O}_{\text {ads }}$ with $\mathrm{z}=1.9$ and, $\mathrm{Mo}_{2} \mathrm{Ti}_{1.1} \mathrm{C}_{1.6} \mathrm{O}(\mathrm{I})_{0.8} \mathrm{O}(\mathrm{II})_{1.2} \mathrm{O}(\mathrm{III})_{1.1}(\mathrm{OH})_{1.0} \mathrm{~F}_{0.1} \cdot 0.3 \mathrm{H}_{2} \mathrm{O}_{\text {ads }}$ and $\mathrm{z}=2.0$. We take the fact that $\mathrm{z}>2$ to be indirect evidence for the substitution of $\mathrm{C}$ by $\mathrm{O}$ in these MXenes.

XPS analysis clearly showed that the harsh conditions needed to produce these MXenes results in significant oxidation of the flakes. The use of TBAOH for delamination resulted in more oxidation as well as the loss of $-\mathrm{F}$ and $\mathrm{H}_{2} \mathrm{O}_{\text {ads. }}$. This is important when specific properties are sought that in most cases assume the MXenes films/powders to be pure, when in fact they are not. Also, in some applications, like catalysis, the effect of having more than $30 \%$ of a transition metal oxide on properties needs to be carefully determined and accounted for. Lastly, and as importantly, more work, both theoretical and experimental needs to be carried out to understand the effect of having O occupying $\mathrm{C}$ sites. 


\section{Acknowledgments:}

We acknowledge the support from the Swedish Research Council (Project Grant No. 621-20144890 and 642-2013-8020). J.R. and P.E acknowledge support from the Knut and Alice Wallenberg (KAW) Foundation for Fellowship Grants and Project funding (KAW 2015.0043), and from the Swedish Government Strategic Research Area in Materials Science on Functional Materials at Linköping University (Faculty Grant SFO-Mat-LiU No. 2009-00971). The Swedish Foundation for Strategic Research (SSF) is also acknowledged for Project Funding (EM160004).

\section{References}

[1] M. Xu, T. Liang, M. Shi, H. Chen, Graphene-like two-dimensional materials, Chem. Rev. (Washington, DC, U. S.), 113 (2013) 3766-3798.

[2] K.S. Novoselov, A.K. Geim, S.V. Morozov, D. Jiang, Y. Zhang, S.V. Dubonos, I.V. Grigorieva, A.A. Firsov, Electric field effect in atomically thin carbon films, Science, 306 (2004) 666-669.

[3] D. Pacilé, J.C. Meyer, C.O. Girit, A. Zettl, The two-dimensional phase of boron nitride: Fewatomic-layer sheets and suspended membranes, Appl. Phys. Lett., 92 (2008) 133107.

[4] J.N. Coleman, M. Lotya, A. O'Neill, S.D. Bergin, P.J. King, U. Khan, K. Young, A. Gaucher, S. De, R.J. Smith, I.V. Shvets, S.K. Arora, G. Stanton, H.Y. Kim, K. Lee, G.T. Kim, G.S. Duesberg, T. Hallam, J.J. Boland, J.J. Wang, J.F. Donegan, J.C. Grunlan, G. Moriarty, A. Shmeliov, R.J. Nicholls, J.M. Perkins, E.M. Grieveson, K. Theuwissen, D.W. McComb, P.D. Nellist, V. Nicolosi, Two-dimensional nanosheets produced by liquid exfoliation of layered materials, Science, 331 (2011) 568-571.

[5] R. Ma, T. Sasaki, Nanosheets of oxides and hydroxides: Ultimate 2D charge-bearing functional crystallites, Adv. Mater., 22 (2010) 5082-5104.

[6] P. Vogt, P. De Padova, C. Quaresima, J. Avila, E. Frantzeskakis, M.C. Asensio, A. Resta, B. Ealet, G. Le Lay, Silicene: compelling experimental evidence for graphenelike twodimensional silicon, Phys. Rev. Lett., 108 (2012) 155501.

[7] H. Liu, A.T. Neal, Z. Zhu, Z. Luo, X. Xu, D. Tománek, P.D. Ye, Phosphorene: an unexplored 2D semiconductor with a high hole mobility, ACS Nano, 8 (2014) 4033-4041.

[8] M. Dávila, L. Xian, S. Cahangirov, A. Rubio, G. Le Lay, Germanene: a novel two-dimensional germanium allotrope akin to graphene and silicene, New Journal of Physics, 16 (2014) 095002.

[9] M. Naguib, M. Kurtoglu, V. Presser, J. Lu, J. Niu, M. Heon, L. Hultman, Y. Gogotsi, M.W. Barsoum, Two-dimensional nanocrystals produced by exfoliation of $\mathrm{Ti}_{3} \mathrm{AlC}_{2}$, Adv. Mater., 23 (2011) 4248-4253.

[10] M. Naguib, O. Mashtalir, J. Carle, V. Presser, J. Lu, L. Hultman, Y. Gogotsi, M.W. Barsoum, Two-dimensional transition metal carbides, ACS Nano, 6 (2012) 1322-1331.

[11] P. Urbankowski, B. Anasori, T. Makaryan, D. Er, S. Kota, P.L. Walsh, M. Zhao, V.B. Shenoy, M.W. Barsoum, Y. Gogotsi, Synthesis of two-dimensional titanium nitride $\mathrm{Ti}_{4} \mathrm{~N}_{3}$ (MXene), Nanoscale, 8 (2016) 11385-11391. 
[12] M. Naguib, V.N. Mochalin, M.W. Barsoum, Y. Gogotsi, $25^{\text {th }}$ anniversary article: MXenes: a new family of two-dimensional materials, Adv. Mater., 26 (2014) 992-1005.

[13] J. Halim, K.M. Cook, M. Naguib, P. Eklund, Y. Gogotsi, J. Rosen, M.W. Barsoum, X-ray photoelectron spectroscopy of select multi-layered transition metal carbides (MXenes), Appl. Surf. Sci., 362 (2016) 406-417.

[14] B. Anasori, Y. Xie, M. Beidaghi, J. Lu, B.C. Hosler, L. Hultman, P.R. Kent, Y. Gogotsi, M.W. Barsoum, Two-dimensional, ordered, double transition metals carbides (MXenes), ACS Nano, 9 (2015) 9507-9516.

[15] J. Yang, M. Naguib, M. Ghidiu, L.-M. Pan, J. Gu, J. Nanda, J. Halim, Y. Gogotsi, M.W. Barsoum, Two-dimensional Nb-Based $\mathrm{M}_{4} \mathrm{C}_{3}$ solid solutions (MXenes), J. Am. Ceram. Soc., 99 (2016) 660-666.

[16] M. Ghidiu, M. Naguib, C. Shi, O. Mashtalir, L. Pan, B. Zhang, J. Yang, Y. Gogotsi, S.J.L. Billinge, M.W. Barsoum, Synthesis and characterization of two-dimensional $\mathrm{Nb}_{4} \mathrm{C}_{3}$ (MXene), Chem. Commun. (Cambridge, U. K.), 50 (2014) 9517-9520.

[17] J. Halim, S. Kota, M.R. Lukatskaya, M. Naguib, M.Q. Zhao, E.J. Moon, J. Pitock, J. Nanda, S.J. May, Y. Gogotsi, M.W. Barsoum, Synthesis and characterization of 2D molybdenum carbide (MXene), Adv. Funct. Mater., 10 (2016) 3118-3127.

[18] J. Zhou, X. Zha, F.Y. Chen, Q. Ye, P. Eklund, S. Du, Q. Huang, A two-dimensional zirconium carbide by Selective etching of $\mathrm{Al}_{3} \mathrm{C}_{3}$ from nanolaminated $\mathrm{Zr}_{3} \mathrm{Al}_{3} \mathrm{C}_{5}$, Angew. Chem. Int. Ed., 55 (2016) 5008-5013.

[19] Q. Tao, M. Dahlqvist, J. Lu, S. Kota, R. Meshkian, J. Halim, J. Palisaitis, L. Hultman, M.W. Barsoum, P.O. Persson, J. Rosen, Two-dimensional Mo ${ }_{1 .}{ }_{3} \mathrm{C}$ MXene with divacancy ordering prepared from parent 3D laminate with in-plane chemical ordering, Nature communications, 8 (2017) 14949.

[20] R. Meshkian, L.-Å. Näslund, J. Halim, J. Lu, M.W. Barsoum, J. Rosen, Synthesis of twodimensional molybdenum carbide, $\mathrm{Mo}_{2} \mathrm{C}$, from the gallium based atomic laminate $\mathrm{Mo}_{2} \mathrm{Ga}_{2} \mathrm{C}$, Scr. Mater., 108 (2015) 147-150.

[21] M. Alhabeb, K. Maleski, T.S. Mathis, A. Sarycheva, C.B. Hatter, S. Uzun, A. Levitt, Y. Gogotsi, Selective etching of silicon from $\mathrm{Ti}_{3} \mathrm{SiC}_{2}$ (MAX) produces 2D titanium carbide (MXene), Angew. Chem. Int. Ed., 57 (2018) 5444-5448.

[22] M.W. Barsoum, MAX Phases: Properties of machinable ternary carbides and nitrides, John Wiley \& Sons 2013.

[23] M. Ghidiu, M.R. Lukatskaya, M.Q. Zhao, Y. Gogotsi, M.W. Barsoum, Conductive twodimensional titanium carbide 'clay' with high volumetric capacitance, Nature, 516 (2014) 7881.

[24] M. Ghidiu, J. Halim, S. Kota, D. Bish, Y. Gogotsi, M.W. Barsoum, Ion-exchange and cation solvation reactions in $\mathrm{Ti}_{3} \mathrm{C}_{2}$ MXene, Chem. Mater., 28 (2016) 3507-3514.

[25] J. Halim, M.R. Lukatskaya, K.M. Cook, J. Lu, C.R. Smith, L.-Å. Näslund, S.J. May, L. Hultman, Y. Gogotsi, P. Eklund, M.W. Barsoum Transparent conductive two-dimensional titanium carbide epitaxial thin films, Chem. Mater., 26 (2014) 2374-2381.

[26] Y. Xie, M. Naguib, V.N. Mochalin, M.W. Barsoum, Y. Gogotsi, X. Yu, K.W. Nam, X.Q. Yang, A.I. Kolesnikov, P.R. Kent, Role of surface structure on Li-ion energy storage capacity of two-dimensional transition-metal carbides, J. Am. Chem. Soc., 136 (2014) 6385-6394. 
[27] X. Liang, A. Garsuch, L.F. Nazar, Sulfur cathodes based on conductive MXene nanosheets for high-performance lithium-sulfur batteries, Angew. Chem. Int. Ed., 54 (2015) 3907-3911.

[28] D. Er, J. Li, M. Naguib, Y. Gogotsi, V.B. Shenoy, $\mathrm{Ti}_{3} \mathrm{C}_{2} \mathrm{MXene}$ as a high capacity electrode material for metal (Li, Na, K, Ca) ion batteries, ACS Appl. Mater. Interfaces, 6 (2014) 1117311179.

[29] M.R. Lukatskaya, O. Mashtalir, C.E. Ren, Y. Dall'Agnese, P. Rozier, P.L. Taberna, M. Naguib, P. Simon, M.W. Barsoum, Y. Gogotsi, Cation intercalation and high volumetric capacitance of two-dimensional titanium carbide, Science, 341 (2013) 1502-1505.

[30] X. Xie, S. Chen, W. Ding, Y. Nie, Z. Wei, An extraordinarily stable catalyst: Pt NPs supported on two-dimensional $\mathrm{Ti}_{3} \mathrm{C}_{2} \mathrm{X}(\mathrm{X}=\mathrm{OH}, \mathrm{F})$ nanosheets for oxygen reduction reaction, Chem. Commun. (Cambridge, U. K.), 49 2013, 10112-10114.

[31] O. Mashtalir, K. Cook, V. Mochalin, M. Crowe, M. Barsoum, Y. Gogotsi, Dye adsorption and decomposition on two-dimensional titanium carbide in aqueous media, Journal of Materials Chemistry A, 2 (2014) 14334-14338.

[32] Q. Peng, J. Guo, Q. Zhang, J. Xiang, B. Liu, A. Zhou, R. Liu, Y. Tian, Unique lead adsorption behavior of activated hydroxyl group in two-dimensional titanium carbide, J. Am. Chem. Soc., 136 (2014) 4113-4116.

[33] C.E. Ren, K.B. Hatzell, M. Alhabeb, Z. Ling, K.A. Mahmoud, Y. Gogotsi, Charge- and SizeSelective Ion Sieving Through Ti3C2Tx MXene Membranes, The Journal of Physical Chemistry Letters, 6 (2015) 4026-4031.

[34] J. Chen, K. Chen, D. Tong, Y. Huang, J. Zhang, J. Xue, Q. Huang, T. Chen, CO 2 and temperature dual responsive "Smart" MXene phases, Chem. Commun. (Cambridge, U. K.), 51 (2015) 314-317.

[35] B. Anasori, J. Halim, J. Lu, C.A. Voigt, L. Hultman, M.W. Barsoum, $\mathrm{Mo}_{2} \mathrm{TiAlC}_{2}$ : A new ordered layered ternary carbide, Scr. Mater., 101 (2014) 5-7.

[36] B. Anasori, M. Dahlqvist, J. Halim, E.J. Moon, J. Lu, B.C. Hosler, N.C. El'ad, S.J. May, L. Hultman, P. Eklund, Johanna Rosen, Michel W. Barsoum, Experimental and theoretical characterization of ordered MAX phases $\mathrm{Mo}_{2} \mathrm{TiAlC}_{2}$ and $\mathrm{Mo}_{2} \mathrm{Ti}_{2} \mathrm{AlC}_{3}, \mathrm{~J}$. Appl. Phys., 118 (2015) 094304.

[37] J. Halim, E.J. Moon, P. Eklund, J. Rosen, M.W. Barsoum, T. Ouisse, Variable range hopping and thermally activated transport in molybdenum-based MXenes, Phys Rev B, 98 (2018) 104202.

[38] Y. Dall'Agnese, M.R. Lukatskaya, K.M. Cook, P.-L. Taberna, Y. Gogotsi, P. Simon, High capacitance of surface-modified 2D titanium carbide in acidic electrolyte, Electrochem. Commun., 48 (2014) 118-122.

[39] H. Lind, J. Halim, S. Simak, J. Rosen, J. Rosen, Investigation of vacancy-ordered $\mathrm{Mo}_{1.33} \mathrm{C}$ MXene from first principles and x-ray photoelectron spectroscopy, Physical Review Materials, 1 (2017) 044002.

[40] B. Anasori, C. Shi, E.J. Moon, Y. Xie, C.A. Voigt, P.R. Kent, S.J. May, S.J. Billinge, M.W. Barsoum, Y. Gogotsi, Control of electronic properties of 2D carbides (MXenes) by manipulating their transition metal layers, Nanoscale Horizons, 1 (2016) 227-234.

[41] N.M. Caffrey, Effect of mixed surface terminations on the structural and electrochemical properties of two-dimensional $\mathrm{Ti}_{3} \mathrm{C}_{2} \mathrm{~T}_{2}$ and $\mathrm{V}_{2} \mathrm{CT}_{2}$ MXenes multilayers, Nanoscale, 10 (2018) 13520-13530. 
[42] I. Persson, L.-̊̊. Näslund, J. Halim, M.W. Barsoum, V. Darakchieva, J. Palisaitis, J. Rosen, P.O.A. Persson, On the organization and thermal behavior of functional groups on $\mathrm{Ti}_{3} \mathrm{C}_{2}$ MXene surfaces in vacuum, 2D Materials, 5 (2017) 015002.

[43] R. Patil, M. Uplane, P. Patil, Electrosynthesis of electrochromic molybdenum oxide thin films with rod-like features, Int. J. Electrochem. Sci, 3 (2008) 259-265.

[44] N.A. Dhas, A. Gedanken, Characterization of sonochemically prepared unsupported and silica-supported nanostructured pentavalent molybdenum oxide, The Journal of Physical Chemistry B, 101 (1997) 9495-9503.

[45] O. Marin-Flores, L. Scudiero, S. Ha, X-ray diffraction and photoelectron spectroscopy studies of $\mathrm{MoO}_{2}$ as catalyst for the partial oxidation of isooctane, Surf. Sci., 603 (2009) 2327-2332.

[46] D.O. Scanlon, G.W. Watson, D. Payne, G. Atkinson, R. Egdell, D. Law, Theoretical and experimental study of the electronic structures of $\mathrm{MoO}_{3}$ and $\mathrm{MoO}_{2}$, The Journal of Physical Chemistry C, 114 (2010) 4636-4645.

[47] J. Baltrusaitis, B. Mendoza-Sanchez, V. Fernandez, R. Veenstra, N. Dukstiene, A. Roberts, N. Fairley, Generalized molybdenum oxide surface chemical state XPS determination via informed amorphous sample model, Appl. Surf. Sci., 326 (2015) 151-161.

[48] G. Greczynski, D. Primetzhofer, L. Hultman, Reference binding energies of transition metal carbides by core-level x-ray photoelectron spectroscopy free from $\mathrm{Ar}^{+}$etching artefacts, Appl. Surf. Sci., 436 (2018) 102-110.

[49] S. Ramanathan, S. Oyama, New catalysts for hydroprocessing: transition metal carbides and nitrides, The Journal of Physical Chemistry, 99 (1995) 16365-16372.

[50] P. Delporte, C. Pham-Huu, P. Vennegues, M.J. Ledoux, J. Guille, Physical characterization of molybdenum oxycarbide catalyst; TEM, XRD and XPS, Catal. Today, 23 (1995) 251-267.

[51] L. Óvári, J. Kiss, Angle-resolved XPS investigations of the interaction between $\mathrm{O}_{2}$ and $\mathrm{Mo}_{2} \mathrm{C} / \mathrm{Mo}$ (100), Vacuum, 80 (2005) 204-207.

[52] Á. Koós, A. Oszko, F. Solymosi, A photoelectron spectroscopic study of the carburization of $\mathrm{MoO}_{3}$, Appl. Surf. Sci., 253 (2007) 3022-3028.

[53] M. Naguib, R.R. Unocic, B.L. Armstrong, J. Nanda, Large-scale delamination of multi-layers transition metal carbides and carbonitrides "MXenes", Dalton Trans., 44 (2015) 9353-9358.

[54] J. Halim, An X-ray photoelectron spectroscopy study of multilayered transition metal carbides (MXenes), in, Drexel University, 2016.

[55] C.C. Lai, R. Meshkian, M. Dahlqvist, J. Lu, L.Å. Näslund, O. Rivin, E.N. Caspi, O. Ozeri, L. Hultman, P. Eklund, M.W. Barsoum, J. Rosen, Structural and chemical determination of the new nanolaminated carbide $\mathrm{Mo}_{2} \mathrm{Ga}_{2} \mathrm{C}$ from first principles and materials analysis, Acta Mater., 99 (2015) 157-164.

[56] U. Diebold, $\mathrm{TiO}_{2}$ by XPS, Surface Science Spectra, 4 (1996) 227.

[57] M. Ashton, K. Mathew, R.G. Hennig, S.B. Sinnott, Predicted surface composition and thermodynamic stability of MXenes in solution, The Journal of Physical Chemistry C, 120 (2016) 3550-3556.

[58] Y. Yoon, T.A. Le, A.P. Tiwari, I. Kim, M.W. Barsoum, H. Lee, Low temperature solution synthesis of reduced two dimensional $\mathrm{Ti}_{3} \mathrm{C}_{2}$ MXene with paramagnetic behaviour, Nanoscale, 10 (2018) 22429-22438. 
[59] Z. Li, L. Wang, D. Sun, Y. Zhang, B. Liu, Q. Hu, A. Zhou, Synthesis and thermal stability of two-dimensional carbide MXene $\mathrm{Ti}_{3} \mathrm{C}_{2}$, Materials Science and Engineering: B, 191 (2015) 3340. 


\title{
Supplementary Materials for
}

\section{XPS of Cold Pressed Multilayered and Freestanding} Delaminated 2D Thin Films of $\mathrm{Mo}_{2} \mathrm{TiC}_{2} \mathrm{~T}_{\mathrm{z}}$ and $\mathrm{Mo}_{2} \mathrm{Ti}_{2} \mathrm{C}_{3} \mathrm{~T}_{\mathrm{Z}}$ (MXenes)

\author{
Joseph Halim ${ }^{1 \dagger}$, Kevin M. Cook ${ }^{2 \dagger}$, Per Eklund ${ }^{1}$, Johanna Rosen ${ }^{1}$, and Michel W. Barsoum ${ }^{1,2}$
}

${ }^{1}$ Thin Film Physics Division, Department of Physics, Chemistry and Biology (IFM), Linköping University, SE-583 31 Linköping, Sweden.

${ }^{2}$ Materials Engineering Laboratory, Linde Technology Center, Praxair, Inc. a member of the Linde Group, Tonawanda, NY 14150, USA.

${ }^{3}$ Department of Materials Science \& Engineering, Drexel University, Philadelphia, PA 19104, USA.

${ }^{\dagger}$ Authors have contributed equally to this work 


\section{XPS results for cold pressed multilayered and freestanding delaminated thin films of $\mathrm{Mo}_{2} \mathrm{TiC}_{2} \mathrm{~T}_{\mathrm{z}}$ and $\mathrm{Mo}_{2} \mathrm{Ti}_{2} \mathrm{C}_{3} \mathrm{~T}_{\mathrm{z}}$}

Table S1. XPS peak fitting results for $\mathrm{C} 1 \mathrm{~s}$ region for cold pressed multilayered (ML) and delaminated (d) freestanding thin films of $\mathrm{Mo}_{2} \mathrm{TiC}_{2} \mathrm{~T}_{\mathrm{z}}$ and $\mathrm{Mo}_{2} \mathrm{Ti}_{2} \mathrm{C}_{3} \mathrm{~T}_{\mathrm{z}}$.

\begin{tabular}{|c|c|c|c|c|c|}
\hline Sample & $\mathrm{BE}[\mathrm{eV}]^{\mathrm{a}}$ & FWHM $[\mathrm{eV}]^{\mathrm{a}}$ & Fraction & Assigned to & Reference \\
\hline \multirow{3}{*}{$\begin{array}{l}\text { Cold pressed } \\
\text { multilayered }\end{array}$} & 282.5 & 1.0 & 0.23 & C-Mo/Ti-T & [1] \\
\hline & 284.7 & 1.4 & 0.54 & $\mathrm{C}-\mathrm{C}$ & [1] \\
\hline & 285.4 & 1.4 & 0.18 & $\mathrm{CH}_{\mathrm{x}}$ & [1] \\
\hline \multirow{2}{*}{$\mathrm{Mo}_{2} \mathrm{TiC}_{2}$} & 286.2 & 1.4 & 0.03 & $\mathrm{C}-\mathrm{O}$ & [1] \\
\hline & 288.8 & 1.9 & 0.02 & $\mathrm{COO}$ & [1] \\
\hline \multirow{3}{*}{$\begin{array}{l}\text { Delaminated } \\
\text { freestanding }\end{array}$} & 282.8 & 0.8 & 0.20 & C-Mo/Ti-T $x$ & {$[2,3]$} \\
\hline & 284.7 & 1.3 & 0.33 & $\mathrm{C}-\mathrm{C}$ & [4] \\
\hline & 285.4 & 1.3 & 0.39 & $\mathrm{CH}_{\mathrm{x}}$ & [4] \\
\hline \multirow{2}{*}{$\mathrm{Mo}_{2} \mathrm{TiC}_{2}$} & 286.4 & 1.3 & 0.05 & $\mathrm{C}-\mathrm{O}$ & [4] \\
\hline & 289.1 & 2.2 & 0.03 & $\mathrm{COO}$ & [4] \\
\hline \multirow{6}{*}{$\begin{array}{l}\text { Cold pressed } \\
\text { multilayered } \\
\mathrm{Mo}_{2} \mathrm{Ti}_{2} \mathrm{C}_{3}\end{array}$} & 281.9 & 0.8 & 0.12 & C-Ti & [1] \\
\hline & 282.5 & 0.9 & 0.24 & C-Ti/Mo-T & [1] \\
\hline & 284.6 & 1.4 & 0.46 & $\mathrm{C}-\mathrm{C}$ & [1] \\
\hline & 285.3 & 1.4 & 0.11 & $\mathrm{CH}_{\mathrm{x}}$ & [1] \\
\hline & 286.2 & 1.4 & 0.04 & $\mathrm{C}-\mathrm{O}$ & [1] \\
\hline & 288.6 & 2.0 & 0.03 & $\mathrm{COO}$ & [1] \\
\hline \multirow{4}{*}{$\begin{array}{l}\text { Delaminated } \\
\text { freestanding }\end{array}$} & 282.1 & 0.9 & 0.10 & C-Ti & [3] \\
\hline & 282.6 & 1.5 & 0.19 & C-Ti/Mo-T & {$[2,3]$} \\
\hline & 284.6 & 1.5 & 0.57 & $\mathrm{C}-\mathrm{C}$ & [4] \\
\hline & 285.8 & 1.5 & 0.09 & $\mathrm{CH}_{\mathrm{x}}$ & [4] \\
\hline \multirow{2}{*}{$\mathrm{Mo}_{2} \mathrm{Ti}_{2} \mathrm{C}_{3}$} & 286.1 & 1.5 & 0.04 & $\mathrm{C}-\mathrm{O}$ & [4] \\
\hline & 288.7 & 2.0 & 0.01 & $\mathrm{COO}$ & [4] \\
\hline
\end{tabular}


Table S2. XPS peak fitting results for $\mathrm{F} 1 \mathrm{~s}$ region for cold pressed multilayered (ML) and delaminated (d) freestanding thin films of $\mathrm{Mo}_{2} \mathrm{TiC}_{2} \mathrm{~T}_{\mathrm{z}}$ and $\mathrm{Mo}_{2} \mathrm{Ti}_{2} \mathrm{C}_{3} \mathrm{~T}_{\mathrm{z}}$.

\begin{tabular}{|c|c|c|c|c|c|}
\hline Sample & $\mathrm{BE}[\mathrm{eV}]^{\mathrm{a}}$ & FWHM $[\mathrm{eV}]^{\mathrm{a}}$ & Fraction & Assigned to & Reference \\
\hline $\begin{array}{l}\text { Cold pressed } \\
\text { multilayered } \\
\mathrm{Mo}_{2} \mathrm{TiC}_{2}\end{array}$ & 685.2 & 2.0 & 1.0 & C-Mo-F $x$ & [1] \\
\hline $\begin{array}{l}\text { Delaminated } \\
\text { freestanding } \\
\mathrm{Mo}_{2} \mathrm{TiC}_{2}\end{array}$ & $\begin{array}{l}685.1 \\
687.0\end{array}$ & $\begin{array}{l}1.9 \\
2.0\end{array}$ & $\begin{array}{l}0.49 \\
0.51\end{array}$ & $\begin{array}{c}\text { C-Mo-F } \\
\text { AlF }_{x}\end{array}$ & $\begin{array}{l}{[5]} \\
{[6]}\end{array}$ \\
\hline $\begin{array}{c}\text { Cold pressed } \\
\text { multilayered } \\
\mathrm{Mo}_{2} \mathrm{Ti}_{2} \mathrm{C}_{3}\end{array}$ & 685.0 & 1.8 & 1.0 & C-Mo-F & [1] \\
\hline $\begin{array}{c}\text { Delaminated } \\
\text { freestanding } \\
\mathrm{Mo}_{2} \mathrm{Ti}_{2} \mathrm{C}_{3}\end{array}$ & 684.9 & 1.9 & 1.0 & C-Mo-F & [5] \\
\hline
\end{tabular}

Table S3. Summary of elemental global at. $\%$ - including non-MXene entities - of cold pressed multilayered (ML) and freestanding delaminated $(d)$ thin films of $\mathrm{Mo}_{2} \mathrm{TiC}_{2} \mathrm{~T}_{\mathrm{z}}$ and $\mathrm{Mo}_{2} \mathrm{Ti}_{2} \mathrm{C}_{3} \mathrm{~T}_{\mathrm{z}}$.

\begin{tabular}{|ccccccc|}
\hline & $\mathrm{Mo}$ & $\mathrm{Ti}$ & $\mathrm{C}$ & $\mathrm{F}$ & $\mathrm{O}$ & $\mathrm{Al}$ \\
\hline $\mathrm{ML}-\mathrm{Mo}_{2} \mathrm{TiC}_{2}$ & $16.1 \pm 0.6$ & $5.8 \pm 0.2$ & $50.0 \pm 1.2$ & $6.2 \pm 0.8$ & $21.9 \pm 0.6$ & $<0.1$ \\
\hline$d-\mathrm{Mo}_{2} \mathrm{TiC}_{2} \mathrm{~T}_{\mathrm{x}}$ & $15.2 \pm 0.4$ & $7.1 \pm 0.6$ & $40.2 \pm 0.9$ & $1.0 \pm 0.2$ & $34.9 \pm 0.5$ & $1.6 \pm 0.3$ \\
\hline $\begin{array}{c}\mathrm{ML}- \\
\mathrm{Mo}_{2} \mathrm{Ti}_{2} \mathrm{C}_{3} \mathrm{~T}_{\mathrm{x}}\end{array}$ & $19.3 \pm 0.2$ & $11.9 \pm 0.3$ & $43.7 \pm 0.8$ & $3.5 \pm 0.4$ & $21.6 \pm 0.7$ & $<0.1$ \\
\hline$d-\mathrm{Mo}_{2} \mathrm{Ti}_{2} \mathrm{C}_{3}$ & $16.9 \pm 0.9$ & $10.3 \pm 0.2$ & $39.2 \pm 0.6$ & $0.7 \pm 0.2$ & $32.9 \pm 0.7$ & $<0.1$ \\
\hline
\end{tabular}




\section{References:}

[1] J. Halim, An X-ray photoelectron spectroscopy study of multilayered transition metal carbides (MXenes), in, Drexel University, 2016.

[2] S. Myhra, J.A.A. Crossley, M.W. Barsoum, Crystal-chemistry of the $\mathrm{Ti}_{3} \mathrm{AlC}_{2}$ and $\mathrm{Ti}_{4} \mathrm{AlN}_{3}$ layered carbide/nitride phases - characterization by XPS, J. Phys. Chem. Solids, 62 (2001) 811817.

[3] V. Schier, H.J. Michel, J. Halbritter, ARXPS-Analysis of sputtered TiC, SiC and $\mathrm{Ti}_{0.5} \mathrm{Si}_{0.5} \mathrm{C}$ layers, Fresen J Anal Chem, 346 (1993) 227-232.

[4] P.M. Jayaweera, E.L. Quah, H. Idriss, Photoreaction of ethanol on $\mathrm{TiO}_{2}$ (110) single-crystal surface, J. Phys. Chem. C, 111 (2007) 1764-1769.

[5] S.j. Park, C.p. Sun, R. Purtell, A mechanistic study of $\mathrm{SF}_{6} / \mathrm{O}_{2}$ reactive ion etching of molybdenum, Journal of Vacuum Science \& Technology B, 5 (1987) 1372-1373.

[6] K.H. Ernst, D. Grman, R. Hauert, E. Hollander, Fluorine-induced corrosion of aluminum microchip bond Pads - an XPS and AES analysis, Surf. Interface Anal., 21 (1994) 691-696. 